\title{
To Study Presentation of Ocular Cysticercosis and Evaluate Its Demographic Data, Diagnosis, Treatment and Outcome in a Hill Population of Northern India
}

\author{
Deepesh Arora ${ }^{1, *}$, Anuj Sharma ${ }^{1}$, Ratish Raman ${ }^{2}$, Ankit Parasher ${ }^{3}$, Chinky Sharma ${ }^{4}$, \\ Devesh Sharma $^{5}$, Bhawna Tiwari ${ }^{6}$, Himanshu Arora ${ }^{7}$, Abhishek Kumar ${ }^{8}$, Kanika Gupta9, \\ Niyaaz Ahmad $^{10}$, Sulekha Nautiyal ${ }^{11}$, Surbhi Verma ${ }^{12}$, Deepak Anthwal ${ }^{13}$, Dinesh Sharma ${ }^{14}$ \\ ${ }^{1}$ Department of Vitreo-Retina, Amritsar Eye Clinic, Dehradun, India \\ ${ }^{2}$ Department of Radiodiagnosis, Teerthankar Mahaveer Medical College and Research Centre, Moradabad, India \\ ${ }^{3}$ Department of Radiodiagnosis, Parashers Pathology and Imaging Centre, Dehradun, India \\ ${ }^{4}$ Department of General Medicine, Teerthankar Mahaveer Medical College and Research Centre, Moradabad, India \\ ${ }^{5}$ Department of Cornea and Refractive Surgery, Amritsar Eye clinic, Dehradun, India \\ ${ }^{6}$ Department of Oculoplasty and Reconstructive Surgery, Amritsar Eye clinic, Dehradun, India \\ ${ }^{7}$ Department of Glaucoma, Amritsar Eye clinic, Dehradun, India \\ ${ }^{8}$ Department of Cataract and Microsurgery, Amritsar Eye clinic, Dehradun, India \\ ${ }^{9}$ Department of Paediatric Ophthalmology, Amritsar Eye clinic, Dehradun, India \\ ${ }^{10}$ Department of Medicine, Shri Guru Ram Rai Institute of Medical and Health Sciences, Dehradun, India \\ ${ }^{11}$ Department of Microbiology, Shri Guru Ram Rai Institute of Medical and Health Sciences, Dehradun, India \\ ${ }^{12}$ Department of Cornea and Refractive Surgery, Sadguru Netra Chikitsalaya, Chirakoot, India \\ ${ }^{13}$ Department of Retina-Vitreous, Aravind Eye Hospital, Coimbatore, India \\ ${ }^{14}$ Department of Cataract and Refractive Surgery, Amritsar Eye clinic, Dehradun, India
}

\section{Email address:}

drda198591@gmail.com (D. Arora),dr.anuj18@gmail.com (A. Sharma), drratishraman@gmail.com (R. Raman), docankitparashar@gmail.com (A. Parasher),chnkysharma2011@gmail.com (C. Sharma),drdevesh@amritsareyeclinic.com (D. Sharma), drbhavnatiwari75@rediffmail.com(B. Tiwari),drhimanshuarora@outlook.com (H. Arora), drabhi09@gmail.com (A. Kumar), dr.kanika_021987@yahoo.com (K. Gupta), niyaazahmad5419@gmail.com (N. Ahmad), sulekhahatwal@gmail.com (S. Nautiyal), drsurabhi246@gmail.com (S. Verma), deepakanthwal2008@gmail.com (D. Anthwal), drdineshsharma@rediffmail.com (D. Sharma) ${ }^{*}$ Corresponding author

\section{To cite this article:}

Deepesh Arora, Anuj Sharma, Ratish Raman, Ankit Parasher, Chinky Sharma, Devesh Sharma, Bhawna Tiwari, Himanshu Arora, Abhishek Kumar, Kanika Gupta, Niyaaz Ahmad, Sulekha Nautiyal, Surbhi Verma, Deepak Anthwal, Dinesh Sharma. To Study Presentation of Ocular Cysticercosis and Evaluate Its Demographic Data, Diagnosis, Treatment and Outcome in a Hill Population of Northern India. International Journal of Ophthalmology \& Visual Science. Vol. 6, No. 2, 2021, pp. 128-143. doi: 10.11648/j.ijovs.20210602.21

Received: June 1, 2021; Accepted: June 1, 2021; Published: June 22, 2021

\begin{abstract}
Aim: To study presentation of ocular cysticercosis and to evaluate its demographic data, diagnosis, treatment and outcome in hill population of Northern India. Materials and methods: This is a retrospective study carried out in Dehradun, Uttarakhand in a tertiary eye care hospital over 4 years from 2016-2020. The study involved 38 patients who presented with unilateral eye disease and were diagnosed to have ocular or adenexal cysticercosis. We analysed retrospectively their geographical data, clinical presentation, serology, imaging, response to treatment and clinical outcome. Results: Age of patients ranged from 16-54 years. Male to female ratio was 1:3.75. Total no. of eyes affected were 38. All were unilateral presentation. 30 eyes $(78.94 \%)$ presented with extraocular cysticercosis and 8 eyes $(21.05 \%)$ with intraocular cysticercosis. 27 of the patients $(71.05 \%)$ were from lower socioeconomic status with poor hygiene and sanitation conditions. 32 (89.21\%) patients gave history of association with non-vegetarian diet. Extraocular cysticercosis group had restriction of ocular motility as most prevalent presentation seen in 16 eyes $(53.33 \%)$ and proptosis as the most prevalent sign seen in 17 eyes (56.66\%). Cyst
\end{abstract}


prevalence was most frequently detected in superior rectus muscle seen in 14 eyes (53.84\%). Intraocular cysticercosis group had blurring of vision as the most prevalent presenting symptom in 8 eyes (100.0\%). Panuveitis in 6 eyes (75\%) and presence of subretinal cyst in 4 eyes $(50 \%)$ was the most prevalent sign seen in intraocular cysticercosis group. Enzyme linked immunosorbent assay test confirmed serology in 35 cases $(92.10 \%)$. The USG B-scan detected presence of scolex in 36 eyes (94.73\%). Magnetic resonance imaging (MRI) confirmed deep seated extraocular cysticercosis lesions and neurocysticercosis (NCC) undetected by computerized tomography (CT). CT was diagnostic for NCC in 5 cases (13.15\%). Oral Albendazole and prednisolone were successful in management of extraocular cysticercosis. Intraocular cysticercosis was treated well with pars plana vitrectomy surgery with good visual recovery. Conclusion: Extraocular cysticercosis was more prevalent than intraocular cysticercosis. Early diagnosis and treatment made a difference in final outcome of the two groups. Imaging studies of orbital B-scan ultrasonography (USG B scan), CT and MRI with immune serological test of enzyme linked immunosorbet assay (ELISA) and Western blot for anticysticercus antibodies helped in confirming the diagnosis. Extraocular cysticercosis can be managed well medically with good clinical outcome. Intraocular cysticercosisis is best treated surgically. Safer and modern vitreoretinal surgical techniques promise good surgical outcome and visual recovery. Timely intervention and frequent postoperative follow up would help in keeping a watch on development of complications and maintenance of good vision.

Keywords: Albendazole, Cysticercosis, Corticosteroids, ELISA, Magnetic Resonance Imaging, USG Bscan, Parsplana Vitrectomy

\section{Introduction}

Human cysticercosis is a parasitic infection caused by Taenia solium cysticerci of cellulose type, the larval form of pork tapeworm "Taenia solium". The presence of tapeworm carrier in the household is the main risk factor in acquiring human and swine cysticercosis [1]. The condition is a major public health problem in developing countries [2, 3, 4]. Infestation by pork tapeworm is commonly seen in countries of South and Central America, Mexico, Philippines, India, Eastern Europe, Southeast Asia and Russia and it is rare in Great Britain and United States [2, $3,4]$. Recently documented data has shown a rise in cysticercosis in the southwest part of United States and is believed to be related to heavy immigration from endemic areas with a large number detected in Los Angeles County [5]. Human cysticercosis primarily affects the central nervous system (CNS) presenting as neurocysticercosis (NCC) and is responsible for causing epilepsy in $50 \%$ of Indian patients who present with partial seizures [6]. It also affects the eyes causing ocular cysticercosis $[1,5]$ constituting $12.8-46 \%$ of infected patients [7]. Most common site for ocular cysticercosis as per western studies is documented as subretinal space [8] in contrast to Indian studies where orbit has been considered the most common site $[9,10]$ The purpose behind this study was to define the already existing and changing trends of ocular cysticercosis in relation to its presentation, treatment and outcome in a hill population in northern India at a tertiary eye care centre. Data related to ocular cysticercosis was analysed retrospectively with emphasis on age, gender, socioeconomic status, sanitation, hygiene, location of cyst, modes of clinical presentation, management and eventual outcome.

\section{Patients and Methods}

The retrospective study included 38 patients diagnosed with ocular cysticercosis from 2016 to 2020 at Amritsar Eye Clinic, tertiary eye care centre, in Uttarakhand, India. All patients had a detailed eye examination which included visual acuity, slitlamp biomicroscopy with 78D biconvex lens and indirect ophthalmoscopy. A physical and neurological examination was adviced in all case. Suspected case underwent imaging which included clinical photography, Ultrasound A-scan, Bscan for suspicious intraocular and subretinal pathology. Computerized tomography (CT) and magnetic resonance imaging (MRI) were used to diagnose case of myocysticercosis and neurocysticercosis. Nidek-3000A Echoscan depicted high amplitude spikes corresponding to cyst wall and scolex. USG- B Scan (Nidek-3000A Echoscan) displayed a distinct picture of sonolucent area with well demarcated anterior and posterior margins (Figure 1) along with the presence of central ecodense, curvilinear and highly reflective structure suggestive of scolex with in the cyst in the affected muscle and subretinal space. Fundus flourescein angiography (FFA) was helpful in delineating a clear limit for the vessel spared swelling or cyst of retina (Figure 2). Computed tomography (CT) and magnetic resonance imaging (MRI) were advised to rule out neurocysticercosis (NCC) or myocysticercosis. Clinical diagnosis for NCC was confirmed on CT scan showing a midline solitary oval hypodense lesion with hyperdense dot suggestive of scolex (Figure 3). MRI with contrast depicted a ring enhancing lesion with central hypodense spot suggestive of scolex revealing typical picture of "hole in dot" appearance involving lateral rectus muscle suggestive of scolex (Figure 4) and it also helped in staging of parasite. MRI confirmed lesions in brain parenchyma (Figure 5) as small and hypodense with peripheral hyperdense rim on FLAIR sequence indicating presence of NCC with perilesional odema. It depicted presence of ring enhancing lesions in brain parenchyma indicating NCC (Figure 6). MRI may shed more light on the type of lesion, its content and surrounding area giving valuable information. (Figures 7, 8, 9, 10). MRI imaging show presence of a lesion involving left frontal region of brain parenchyma suggestive of calcification (Figure 7: susceptibility weighted image (SWI), Figure 8: reverse phase image of SWI, Figure 9: post contrast T1 weighted fat saturation image, Figure 10: perilesional odema with peripheral rim enhancement). 


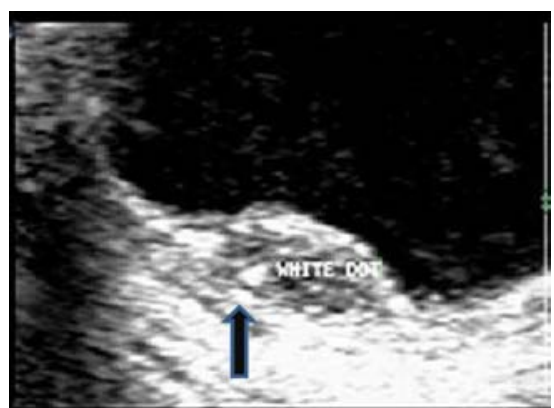

Figure 1. A curvilinear cystic lesion with highly reflective echogenic structure representing the scolex (black arrow).

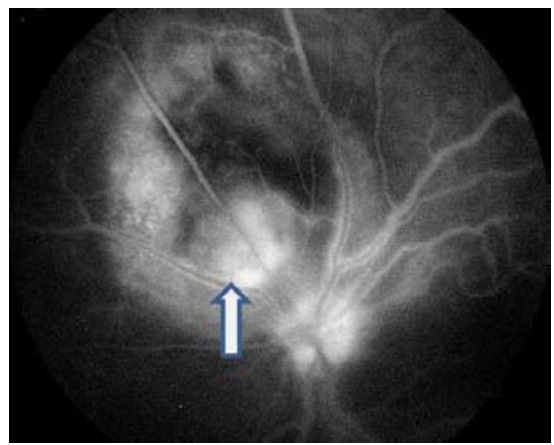

Figure 2. Central zone of fluorescence with stain suggestive of scolex (white arrow) with surrounding zone of hypoflourescence.

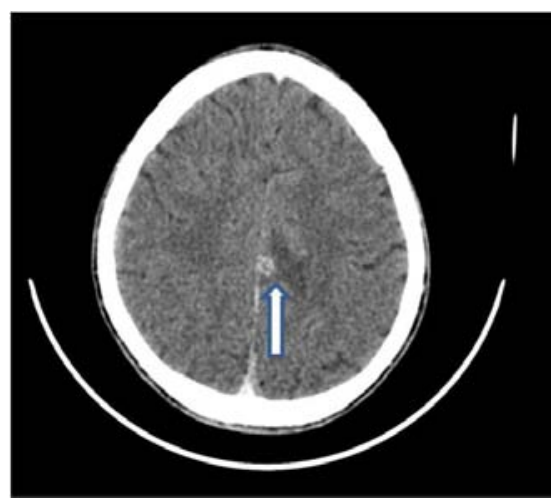

Figure 3. Ring enhancing midline hypodense irregular oval lesion (white arrow) with eccentric hyperdense dot suggestive of scolex surrounded by hyperdense perilesional odema suggestive of "hole in dot appearance".

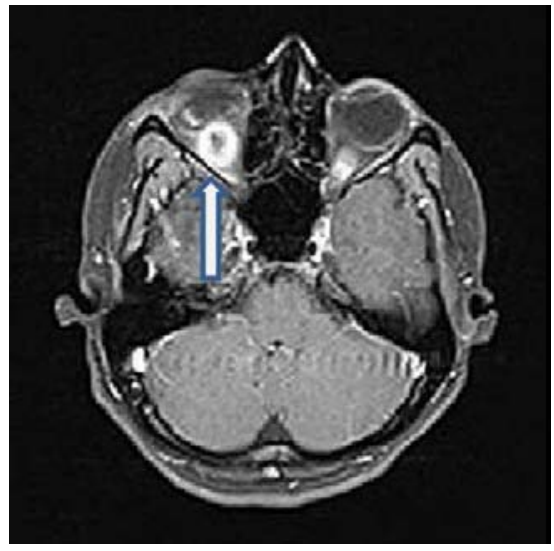

Figure 4. MRI with contrast showing cystic lesion involving lateral rectus muscle with hole in dot appearance (white arrow).

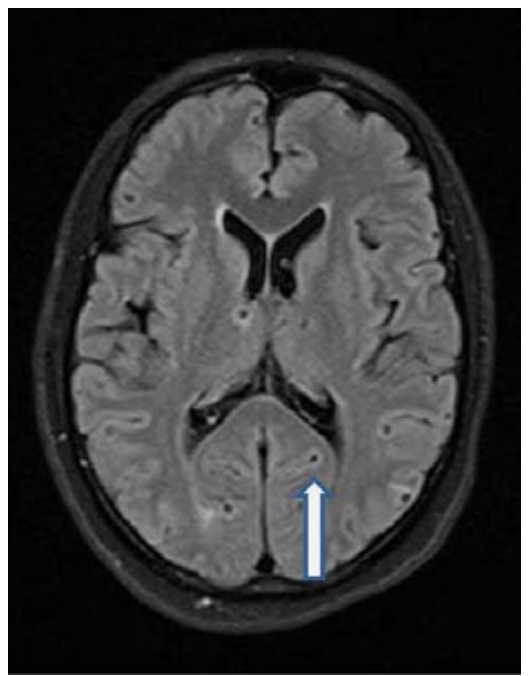

Figure 5. MRI brain parenchyma showing few small hypodense lesions with peripheral hyperdense rim on FLAIR sequence indicating presence of NCC (white arrow) with perilesional odema.

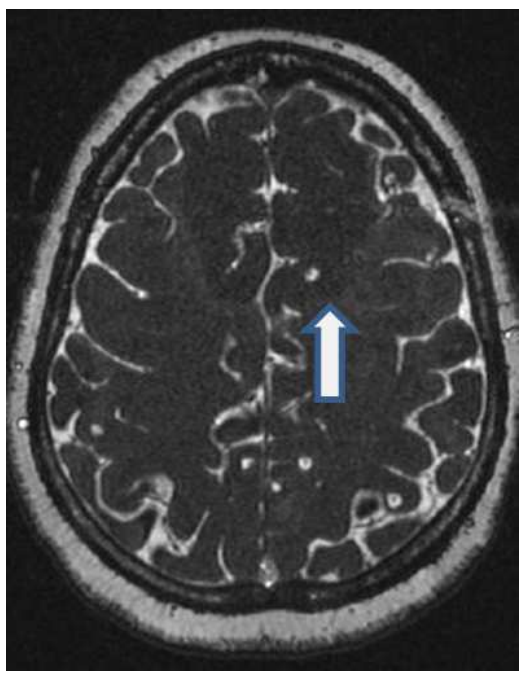

Figure 6. MRI of brain parenchyma showing ring enhancing lesions indicating $N C C$ (white arrow).

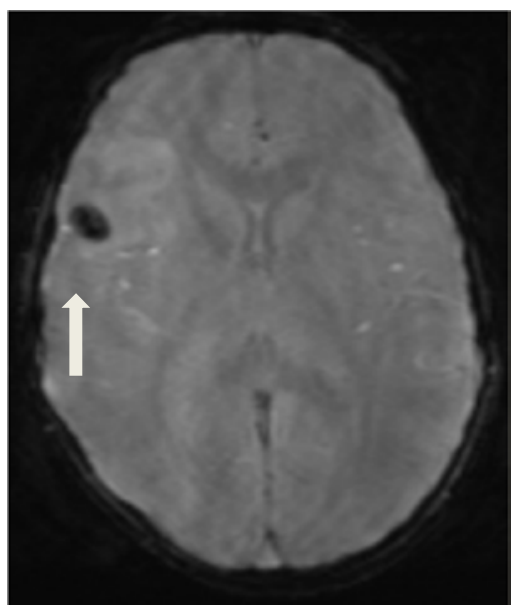

Figure 7. Axial magnitude image of susceptibility weighted imaging (SWI) shows an inhomogenous predominantly hypointense focus in left frontal region suggestive of calcification with a tiny eccentric hypointense dot (white arrow) attached to the wall seen separately within the lesion which is presumed scolex. 


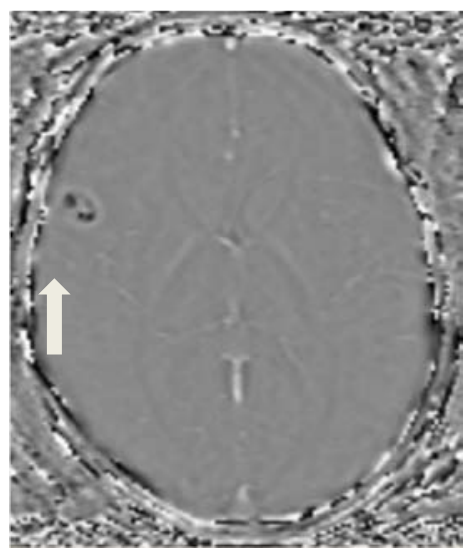

Figure 8. Reverse phase image of SWI suggestive of calcified focus. Axial fluid attenuated inversion recovery (FLAIR) sequence. (white solid arrow).

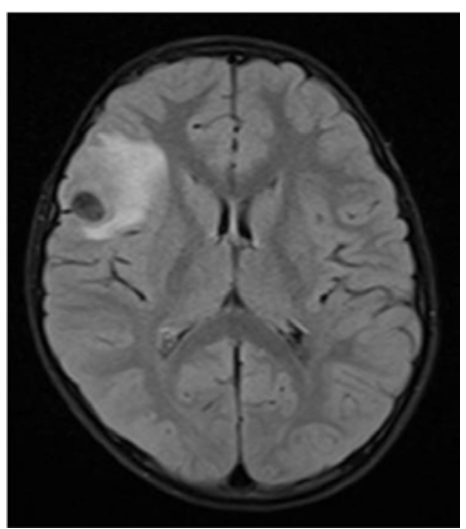

Figure 9. Post contrast T1 weighted fat saturation image showing oval hypodense lesion surrounded by hyperdense area.

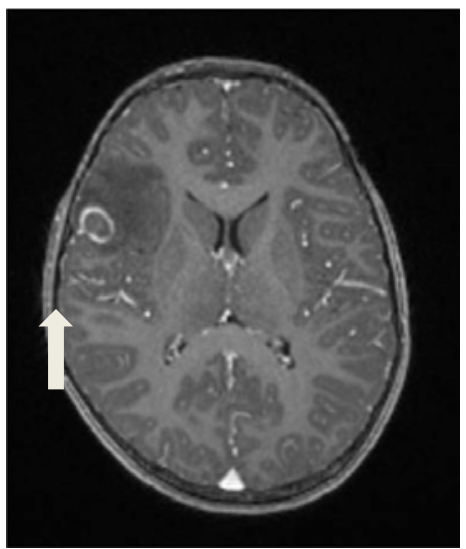

Figure 10. Shows perilesional odema (white arrow) with peripheral rim enhancement around the lesion suggestive of inflammatory changes.

The serum of patients was tested for cysticercal antibodies by Enzyme Linked Immuno-Sorbent Assay technique (ELISA) using Ridascreen kit (r-biopharm). The ridascreen "T. solium" test is an enzyme immunoassay for the qualitative determination of IgG antibodies against "Taenia solium" and its cysticerci (bladder worms) in human serum. Specific antigens have increased ELISA's sensitivity and specificity, though cross reactions may occur requiring confirmation with more specific tests as western blot. Additional laboratory investigations were total leucocyte count (TLC), differential leucocyte count (DLC), absolute eosinophil count (AEC) and erythrocyte sedimentation rate (ESR). The demographic data included age, gender, socioeconomic status, sanitation, hygiene levels, modes of clinical presentations, site of cyst, treatment protocol with visual and clinical outcome of diseased eye. Ocular cysticercosis was further divided into extraocular (Group-A) and intraocular cysticercosis (Group-B).

Table 1. Patient anthropology data.

\begin{tabular}{lll}
\hline \multicolumn{2}{l}{ Total number of patients } & $\mathbf{( 3 8 )}$ \\
\hline 1. & Age at presentation & $16-54$ years \\
2. & Sex ratio M:F & $1: 4.28$ \\
3. & Non Vegetarian Diet & $32(89.21 \%)$ \\
4. & Poor Socioeconomic strata & $27(71.05 \%)$ \\
5. & Poor Hygiene and sanitation & $25(65.78 \%)$ \\
\hline
\end{tabular}

\subsection{Group A: Extraocular Cysticercosis Group}

Extraocular cysticercosis diagnosis was aided by imaging studies. Orbital USG B-scan (Figure 1), CT scan and MRI with contrast helped in detection and confirmation of a cystic lesion with or without presence of scolex. MRI (Figure 5 and Figure 6) / CT brain (Figure 3) were done to rule out NCC and deep seated lesion as seen in lateral rectus muscle (Figure 4) before starting antihelminthic therapy. Serological tests of ELISA-IgM / IgG for cysticercus was done for all patients with extraocular cysticercosis (30 patients). Cases were followed up at 2, 4, 8 and 12 weeks. Medical treatment with oral Albendazole / Praziquantal, which are larvicidal drugs was used in the treatment of cysticercosis. Oral Albendazole $(15 \mathrm{mgm} / \mathrm{kg} /$ day in two divided doses) with Prednisolone $(1 \mathrm{mgm} / \mathrm{kg} /$ day in single dose) was given for 4-6 weeks for orbital cysticercosis group with repeated dosing as clinically warranted. Patients were followed at $(2,4,8$ and 12 weeks) with aim of keeping a watch on their clinical progress. Serial orbital USG B scan is essential for confirmation of cases, to detect presence of cyst or scolex and to keep a check on the primary lesion and inflammed surrounding tissue, with the aim to assess response to treatment. Two patients with conjunctival cyst (Figure 11) required surgical intervention. While treating patients it is important to remember absorption of albendazole is increased with fatty food. Treatment with albendazole may increase inflammation initially as the cyst involutes usually 2-5 days after initiation of therapy leading to variation of clinical states. Concomitant use of steroids was thus indicated.

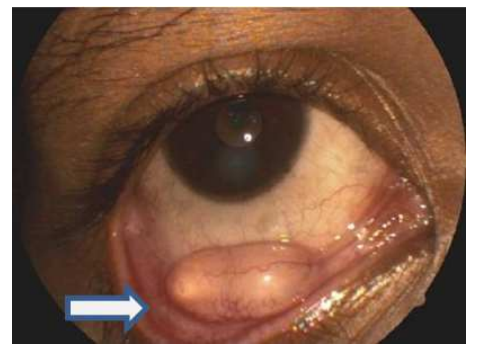

Figure 11. Clinical photograph: depicting subconjunctival cyst (white arrow). 


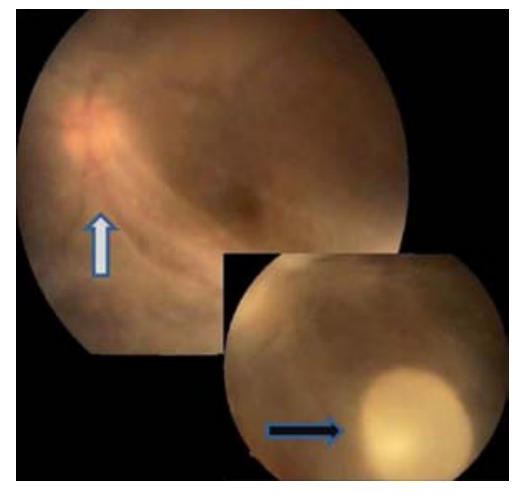

Figure 12. Clinical photograph: Shows dense vitritis with membranes (white arrow) overlying inferior tractional retinal detachment (TRD) along with presence of large solitary intravitreal cyst (approximate size 6 disc diopter) (black arrow).

\subsection{Group B: Intraocular Cysticercosis Group}

Intraocular cysticercosis is best treated with early surgical removal. A transscleral approach can be used for subretinal cysts located anterior to equator and transvitreal approach for intravitreal and subretinal cysts located posterior to equator. Surgery was advised for (Group-B) cases with tractional retinal detachment (TRD) with presence of intravitreal or subretinal cysticercus lesions (Figure 9) and those with ERM (Epiretinal membrane) (case 1, 2, 4, 5, 6, 7, 8). We used a 23 gauge pars plana vitrectomy (PPV) approach. Sclerotomies for PPV surgery were made $4.0 \mathrm{~mm}$ from limbus as all eyes were phakic. After removal of posterior vitreous, a retinotomy was created away from blood vessels by endodiathermy and the cyst was removed from the subretinal space by either flute needle or vitreous cutter, followed by drainage of subretinal fluid, fluid-air exchange, endolaser around retinotomy and silicone oil injection (Figure 19). Encirclage with $2.5 \mathrm{~mm}$ silicone band (No. 240; Labtician) was done after a 360 degree peritomy to support the posterior vitreous base in cases involving tractional retinal detachment (TRD). Topical and oral steroid were used to control panuveitis and subsequent vitritis. Face down positioning was advised postsurgery for tamponade. Since patients in this group had severely compromised visual acuity, postsurgical functional improvement in vision of $>4 / 200$ at 12 weeks final follow up was considered as success criteria in comparison to first outpatient recorded vision.

Table 2. Intraocular cysticercosis (Group-B) Pre and Post treatment visual acuity change in $\%$.

\begin{tabular}{lll}
\hline Group = Intraocular & & \\
\hline Pre treatment vision & Frequency & $\mathbf{\%}$ \\
\hline $1 / 60$ & 1 & $12.5 \%$ \\
$2 / 60$ & 1 & $12.5 \%$ \\
$3 / 60$ & 1 & $12.5 \%$ \\
$4 / 60$ & 2 & $25.0 \%$ \\
$5 / 60$ & 1 & $12.5 \%$ \\
HM & 2 & $25.0 \%$ \\
Total & 8 & $100 \%$ \\
\hline & & \\
\hline Post treatment vision & Frequency & $\%$ \\
\hline $5 / 60$ & 2 & $25.0 \%$ \\
$6 / 24$ & 1 & $12.5 \%$ \\
$6 / 36$ & 3 & $37.5 \%$ \\
$6 / 60$ & 2 & $25.0 \%$ \\
Total & 8 & $100 \%$ \\
\hline
\end{tabular}

Table 3. Extraocular cysticercosis (Group-A) Pre and Post treatment visual acuity change in $\%$.

\begin{tabular}{lll}
\hline Group = Extraocular & & \\
\hline Pre treatment vision & Frequency & $\mathbf{\%}$ \\
\hline $6 / 12$ & 13 & $43.3 \%$ \\
$6 / 18$ & 6 & $20.0 \%$ \\
$6 / 6$ & 2 & $6.7 \%$ \\
$6 / 9$ & 9 & $30.0 \%$ \\
Total & 30 & $100 \%$ \\
\hline & & \\
\hline Post treatment vision & Frequency & $\mathbf{\%}$ \\
\hline $6 / 6$ & 17 & $56.7 \%$ \\
$6 / 6 P$ & 4 & $13.3 \%$ \\
$6 / 9$ & 9 & $30.0 \%$ \\
Total & 30 & $100 \%$ \\
\hline
\end{tabular}

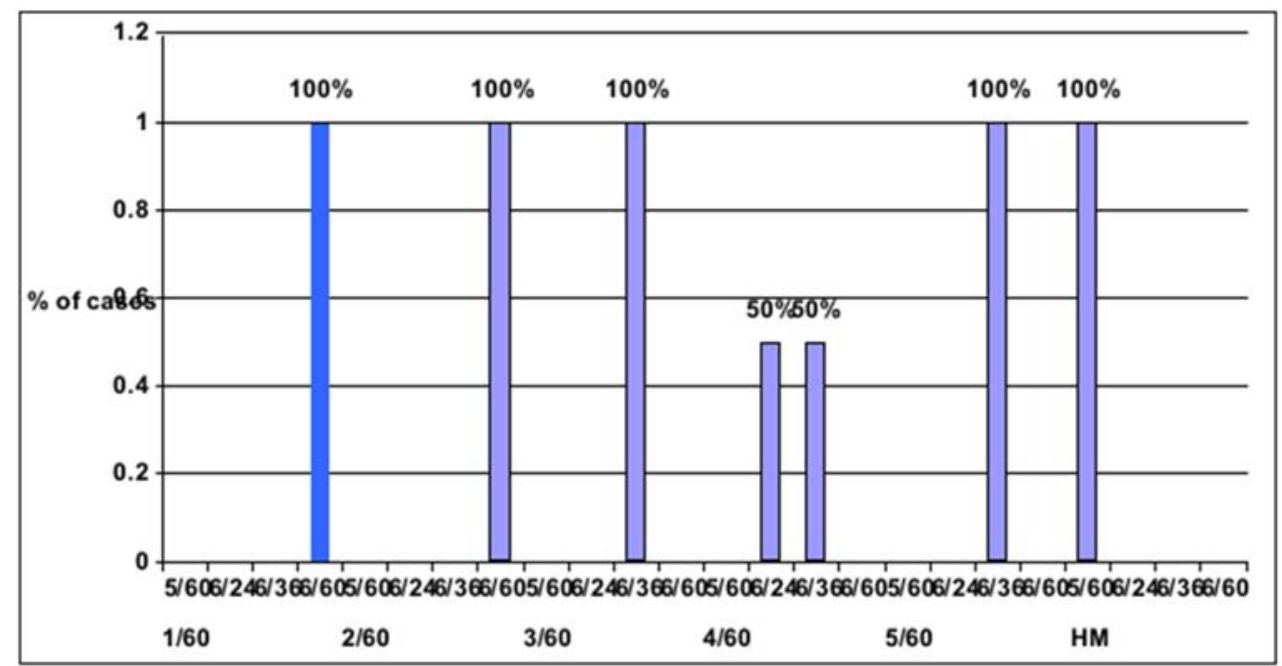

Figure 13. Graph depicting \% of visual change before and after initiation of treatment in Intraocular group (Group-B). 
Table 4. Intraocular Group (Group B) P value calculation for change in visual acuity before and after treatment.

\begin{tabular}{|c|c|c|c|c|c|c|}
\hline \multirow{3}{*}{$\begin{array}{l}\text { Pre treatment } \\
\text { vision }\end{array}$} & \multirow{3}{*}{ Total } & \multicolumn{4}{|c|}{ Post treatment vision } & \multirow{3}{*}{ Pvalue } \\
\hline & & $5 / 60$ & $6 / 24$ & $6 / 36$ & $6 / 60$ & \\
\hline & & Frequency (\%) & Frequency (\%) & Frequency (\%) & Frequency (\%) & \\
\hline $1 / 60$ & 1 & & & & $1(100 \%)$ & \\
\hline $2 / 60$ & 1 & & & & $1(100 \%)$ & \\
\hline $3 / 60$ & 1 & & & $1(100 \%)$ & & \\
\hline $4 / 60$ & 2 & & $1(50.0 \%)$ & $1(50.0 \%)$ & & 0.229 \\
\hline $5 / 60$ & 1 & & & $1(100 \%)$ & & \\
\hline $\mathrm{HM}$ & 2 & $2(100 \%)$ & & & & \\
\hline Total & 8 & $2(25.0 \%)$ & $1(12.5 \%)$ & $3(37.5 \%)$ & $2(25.0 \%)$ & \\
\hline
\end{tabular}

Table 5. Extraocular Group: (Group A) P value calculation for change in visual acuity before and after treatment.

\begin{tabular}{|c|c|c|c|c|c|}
\hline \multirow{3}{*}{ Pre treatment vision } & \multirow{3}{*}{ Total } & \multicolumn{3}{|c|}{ Post treatment vision } & \multirow{3}{*}{ p value } \\
\hline & & $6 / 6$ & $6 / 6 P$ & $6 / 9$ & \\
\hline & & Frequency (\%) & Frequency (\%) & Frequency (\%) & \\
\hline $6 / 12$ & 13 & $7(53.8 \%)$ & $1(7.7 \%)$ & $5(38.5 \%)$ & \\
\hline $6 / 18$ & 6 & $2(33.3 \%)$ & & $4(66.7 \%)$ & \\
\hline $6 / 6$ & 2 & $2(100 \%)$ & & & 0.067 \\
\hline $6 / 9$ & 9 & $6(66.7 \%)$ & $3(33.3 \%)$ & & \\
\hline Total & 30 & $17(56.7 \%)$ & $4(13.3 \%)$ & $9(30.0 \%)$ & \\
\hline
\end{tabular}

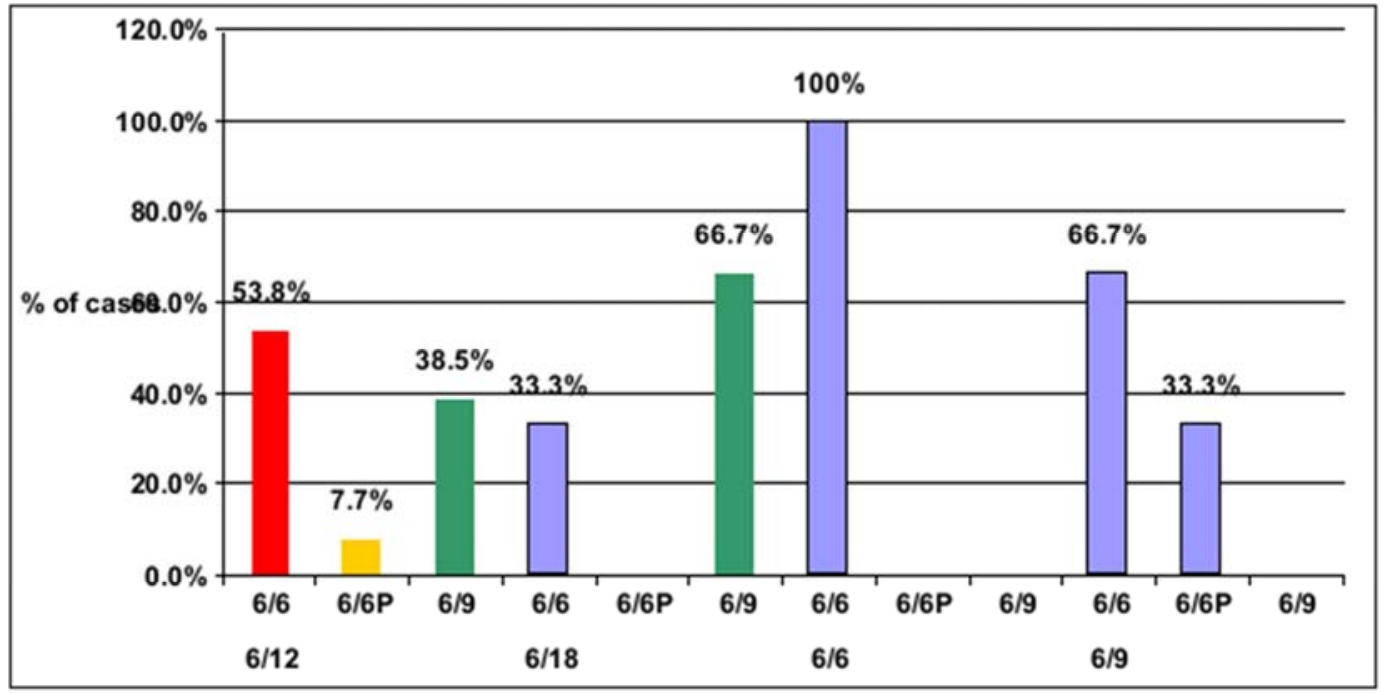

Figure 14. Graph depicting \% of change in visual acuity before and after treatment in Extraocular group (Group-A).

All data was analysed using SPSS software (version 16). Change in visual acuity in both Intraocular and extraocular group were assessed pre and post treatment using their frequencies (number of patient), percentages, mean with standard deviation and coefficient fractions. The change is depicted in the two graph shown above (Figure 13, Figure 14).

\section{Results and Interpretation}

Among the 38 eyes which were assessed and confirmed with ocular cysticercosis, 31 were male $(81.57 \%)$ and 7 $(18.42 \%)$ were female, there ratio being 1:3.75. Age of these patients ranged from 16 to 54 years, 15 of them $(39.47 \%)$ being less than 25 year of age. Among 38 patients 25 $(65.78 \%)$ were from areas with poor sanitation condition and $27(71.05 \%)$ belonged to poor socio-economic strata. Those with non-vegetarian diet constituted 32 (89.21\%) cases and 6
(15.78\%) gave history of being vegetarian. Among 38 patients, $30(78.94 \%)$ belonged to extraocular cysticercosis (Group-A) and 8 (21.05\%) belonged to intraocular cysticercosis (Group-B). All our cases had unilateral presentation.

\subsection{Group-A: Extraocular Cysticercosis Group}

\subsubsection{Presentation of Eye Disease}

Extraocular cysticercosis (EC) patients presented with variability of symptoms. Most prevalant presentation was restriction of ocular motility seen in 16 eyes $(53.33 \%)$, diplopia in 9 eyes $(30.00 \%)$, defective vision in 5 eyes $(16.66 \%)$ and pain, redness with watering seen in 4 eyes (13.33\%). Among clinical signs the most prevalent was proptosis in 17 eyes $(56.66 \%$ ), periocular swelling in 13 eyes (43.33\%), conjunctival swelling in 4 eyes $(13.33 \%)$, lid odema in 3 eyes (10.0\%) and squint in one eye (3.3\%). 
Table 6. Clinical presentation of Involved Eye in Extraocular Cysticercosis: (Group- A) Total no. of Eyes: 30.

\begin{tabular}{lll}
\hline Extraocular cysticercosis & Presentation (no. of eyes) & Frequency (\%) \\
\hline Symptoms & & $(53.33 \%)$ \\
1) Restriction of ocular motility & 16 & $(30.0 \%)$ \\
2) Diplopia & 9 & $(16.66 \%)$ \\
3) Defective vision & 5 & $(13.33 \%)$ \\
4) Pain/redness/watery & 4 & $(56.66 \%)$ \\
Clinical signs & & $(13.33 \%)$ \\
1) Proptosis & 17 & $(10.0 \%)$ \\
2) Periocular swelling & 4 & $(3.3 \%)$ \\
3) Lid odema & 3 & 1 \\
4) Squint & 1 & \\
\hline
\end{tabular}

\subsubsection{Number and Site of Cyst}

The cyst were present in multiple location in the eye, with orbit being the most prevalent site involved with 26 eyes (26/30) (86.66\%). Among four other eyes, conjunctival cyst (Figure 11) was seen in 3 eyes $(10 \%)$ and subconjunctival cyst in one eye $(3.3 \%)$. Among the 26 eyes with orbital cysticercosis, the most prevalent muscle involved in 14 eyes $(53.84 \%)$ was superior rectus, 8 eyes $(30.76 \%)$ had medial rectus involvement, 3 eyes $(11.53 \%)$ had inferior rectus and 1 eye $(3.84 \%)$ had lateral rectus involvement as seen on MRI (Figure 4).

Table 7. Location of cyst in Extraocular Cysticercosis: (Group-A) Total no. of Eyes (30 eyes).

\begin{tabular}{cll}
\hline & Presentation (no. of eyes) & Frequency (\%) \\
\hline 1) Orbital cysticercosis & 26 & $(86.66 \%)$ \\
a) Superior rectus & 14 & $(53.84 \%)$ \\
b) Medial rectus & 8 & $(30.76 \%)$ \\
c) Inferior rectus & 3 & $(11.53 \%)$ \\
d) Lateral rectus & 1 & $(3.84 \%)$ \\
2) Conjunctival cyst & 3 & $(10 \%)$ \\
3) Subconjunctival cyst & 1 & $(3.33 \%)$ \\
\hline
\end{tabular}

\subsubsection{Imaging Modalities and Serology}

A USG B-scan was used as an investigational tool for diagnosis in 30 cases of extraocular cysticercosis and was confirmatory in 28 eyes (28/30) $(93.33 \%)$. Additional imaging of $\mathrm{CT}$ and MRI with contrast were used to detect scolex in other cases. A CT brain was considered mandatory in all cases to rule out NCC lesions prior to starting antihelminthic therapy and was diagnostic and confirmatory for NCC in 3 cases of extraocular cysticercosis (Group-A) (Figure 3). CT detects NCC best in acute stage of disease. MRI contrast ruled out deep seated (Figure 4) and multiple locations of intra orbital lesions ( 2 cases) where both USG B scan and CT had been unable to localize a scolex. MRI was done for 2 other suspicious cases where CT had been unable to detect NCC lesions. MRI confirmed presence of focal odema and scolex in brain parenchyma in these 2 cases. The serum of all patients was tested for cysticercal antibodies in our lab by (ELISA) using Ridascreen kit (r-biopharm). Both $\operatorname{IgG}$ and IgM were tested in all 30 patients with 28 cases showing positivity (93\%). Western blot was carried out in remaining two cases confirming positive serology. Additional Laboratory investigations included total and differential leucocyte count, absolute eosinophil count (AEC), erthrocyte sedimentation rate (ESR). Both AEC (documented range 300-520, normal $<500$ cells $/$ microliter (cells $/ \mathrm{mcL}$ ) and ESR (documented range 20-32 $\mathrm{mm} / \mathrm{hr}$. Normal range for men and women $<50$ years: women $<50$ ESR $0-20 \mathrm{~mm} / \mathrm{hr}$, men $<50$ ESR $0-15 \mathrm{~mm} / \mathrm{hr}$. Range women $>50$ years: ESR 0-30 $\mathrm{mm} / \mathrm{hr}$ and men $>50$ years ESR $0-20 \mathrm{~mm} / \mathrm{hr}$ ) were noted in all cases of extraocular cysticercosis (Group-A).

Table 8. Imaging studies used in diagnosis and confirmation of Cyst, Scolex and NCC in Extraocular cysticercosis (Group A) Total no. of patients (30 patients).

\begin{tabular}{lll}
\hline Imaging studies & No. of patients positive & Frequency (\%) \\
\hline USG B scan for scolex detection & 28 & 1 \\
CT Scan for scolex detection & 2 & $(80 \%)$ \\
MRI contrast (for deep seated orbital lesions) & 3 & $(3.33 \%)$ \\
CT Scan with contrast for confirming (NCC) & 2 & $(10 \%)$ \\
MRI for confirming NCC undetected by CT & $23 \%)$ \\
\hline
\end{tabular}

CAT scan=Computerized axial tomography scan, MRI=Magnetic resonance imaging, NCC $=$ Neurocysticercosis, USG $B$ scan $=$ Ultrasonography brightness scan

\subsubsection{Management Modalities}

Five patients confirmed for NCC, at risk of flare up of brain parenchymal disease were started on phenytoin sodium an antiepileptic medication with oral dexamethasone prior to starting antilarvicidal treatment (Both oral phenytoin sodium 100 milligram and oral dexamethasone 8 milligram were started as thrice daily dosage and adjusted as per clinical state of patient keeping a watch on cyst involution). Medical treatment with oral Albendazole / Praziquantal both of which are larvicidal drugs can be used in the treatment of cysticercosis in humans. We preferred oral Albendazole as first line drug for treatment in all 30 cases (100\%) of extraocular cysticercosis (Group-A). Oral Albendazole $(15 \mathrm{mgm} / \mathrm{kg} /$ day in two divided doses) along with Prednisolone $(1 \mathrm{mgm} / \mathrm{kg} /$ day in single dose) was given for 4-6 
weeks to cases of orbital cysticercosis. Patients were followed at 2, 4, 8 and 12 weeks keeping a watch on their clinical progress. Serial orbital USG B-scan was carried out to keep a check on the primary lesion, assess response of cyst to treatment and to watch the surrounding soft tissue for inflammation. In 4 patients $(13.33 \%)$ with poor response to Albendazole, Praziquantal (40mgm/kg body weight) as single dose therapy was started for four weeks extended to 6 weeks along with oral steroids calculated as per body weight, keeping a watch on cyst involution by USG B-scan. Post treatment follow up presented as minimally restricted ocular motility disorder in 4 patients $(13.33 \%)$, residual diplopia $(3.33 \%)$, and squint $(3.33 \%)$ in 1 patient each. Those with restricted ocular motility were given short course of oral corticosteroids and orthoptic exercises showing promising recovery. Patient with diplopia and strabismus were referred to squint clinic where prism bar along with orthoptic exercises were adviced keeping a close watch on their extraocular movements. Two patients (6.66\%) with conjunctival cyst (Figure 11) required surgical intervention.

Table 9. Extraocular Cysticercosis (Group-A): Management plan and Clinical outcome data. Total no. of patients: (30).

\begin{tabular}{|c|c|c|c|c|c|c|}
\hline $\begin{array}{l}\text { Sr. } \\
\text { No. }\end{array}$ & $\begin{array}{l}\text { Diagnosis/No. } \\
\text { of eyes }\end{array}$ & Medical Treatment & Surgery & Outcome & $\begin{array}{l}\text { Re-Surgery / } \\
\text { change of drugs }\end{array}$ & $\begin{array}{l}6 \text { months outcome } \\
\text { from primary } \\
\text { therapy }\end{array}$ \\
\hline 1 & $\begin{array}{l}\text { Muscle cyst } \\
(26)\end{array}$ & $\begin{array}{l}\text { 1. Oral *Albendazole }(15 \mathrm{mgm} / \mathrm{kg} / \text { day in two } \\
\text { divided doses })(4-6 \mathrm{wks}) \\
2 . * * \text { Oral Steroids }(1 \mathrm{mgm} / \mathrm{kg} / \text { body weight in single } \\
\text { dose) (4-6 wks) }\end{array}$ & Nil & $\begin{array}{l}22 \text { eyes }(84.61 \%) \\
\text { success }\end{array}$ & $\begin{array}{l}4 \text { eyes }(15.38 \%) \\
\text { Oral Praziquantal } \\
(40 \mathrm{mgm} / \text { body } \\
\text { weight in single } \\
\text { dose) }(4-6 \text { weeks })\end{array}$ & Improved clinically \\
\hline 2 & $\begin{array}{l}\text { Conjunctival } \\
\text { cyst (3) }\end{array}$ & $\begin{array}{l}\text { *Oral Albendazole plus **Oral steroids (Dosage as } \\
\text { / Body weight) }\end{array}$ & 2 & Cyst removed totally & Nil & Improved clinically \\
\hline 3 & $\begin{array}{l}\text { Subconjunctival } \\
\text { Cyst (1) }\end{array}$ & $\begin{array}{l}\text { *Oral Albendazole and } * * \text { Systemic steroids } \\
\text { (dosage as/ body weight) }\end{array}$ & Nil & (100\% success) & Nil & Improved clinically \\
\hline 4 & NCC (5) & $\begin{array}{l}\text { Phenytoin sodium } 100 \mathrm{mgm} \text { in three times/day plus } \\
\text { Oral Dexamethasone } 8 \mathrm{mgm} \text { three times daily for } 1 \\
\text { week }\end{array}$ & Nil & $\begin{array}{l}\text { Dosage adjusted as per } \\
\text { clinical improvement at } \\
1 \text { week }\end{array}$ & 1 year & Stable \\
\hline
\end{tabular}

NCC $=$ Neurocysticercosis, $*=$ Oral Albendazole, $* *=$ Oral steroids

\subsection{Group-B: Intraocular Cysticercosis Group}

\subsubsection{Presentation of Disease}

Intraocular cysticercosis (EC) patients presented with variability of symptoms. Most prevalent presentation was blurring of vision in 8 eyes $(100.0 \%)$, redness and pain in 3 eyes $(37.5 \%)$ and headache in 2 eyes $(25 \%)$. Among the clinical signs most prevalent was panuveitis in 6 eyes $(75 \%)$, subretinal cyst in 4 eyes $(50 \%)$, tractional retinal detachment (TRD) in 3 eyes $(35.5 \%)$, posterior uveitis in 2 eyes $(25 \%)$, intravitreal cyst in 1 eye $(12.50 \%)$, one eye with both single intravitreal and subretinal cyst $(12.5 \%)$, exudative retinal detachment in 1 eye $(12.5 \%)$ and chorioretinitis in 1 eye $(12.5 \%)$.

\subsubsection{Number and Site of Cyst}

Cyst were located maximally in subretinal space in 4 eyes $(50.0 \%)$ followed by single cyst in intravitreal space of one eye $(12.50 \%)$ and presence of one eye $(12.5 \%)$ with single cyst located one each in intravitreal and subretinal space (case 2).

Table 10. Clinical presentation of Involved Eye in Intraocular Cysticercosis: (Group-B) Total no. of Eyes (8).

\begin{tabular}{lll}
\hline Symptoms & Presentation (no. of eyes) & Frequency (\%) \\
\hline 1) Blurring of vision & 8 & $(100 \%)$ \\
2) Redness \& pain & 3 & $(37.5 \%)$ \\
3) Headache & 2 & $(25 \%)$ \\
Clinical signs & 6 & $(75 \%)$ \\
1) Panuveitis & 4 & $(50 \%)$ \\
2) Subretinal cyst & 3 & $(35.50 \%)$ \\
3) Traction retinal detachment & $(25.0 \%)$ \\
4) Posterior Uveitis & $(12.50 \%)$ \\
5) Intravitreal cyst & $(12.50 \%)$ \\
6) Intravitreal and subretinal cyst combination & & \\
7) Exudative retinal detachment & 1 & $(12.50 \%)$ \\
8) Chorioretinitis & & \\
\hline
\end{tabular}

Table 11. Location of Cyst in Intraocular Cysticercosis: (Group-B) Total No. of Eyes (8).

\begin{tabular}{lll}
\hline Location of cyst & No. of Eyes involved & Frequency (\%) \\
\hline Subretinal space & 4 & $(50 \%)$ \\
Intravitreal space & 1 & $(12.50 \%)$ \\
(One cyst each in) Intravitreal & 1 & $(12.50 \%)$ \\
and subretinal space & 1 & \\
\hline
\end{tabular}

\subsubsection{Imaging Modalities and Serology}

Indirect ophthalmoscopy and slitlamp biomicroscopy were used to arrive at a clinical diagnosis. USG B-scan was done in 8 cases of intraocular cysticercosis revealing a welldefined cystic lesion with presence of echogenic structure representing the scolex in 6 eyes (75\%) (Case 1, 2, 4, 5, 6, 8). 
Two other cases (Cases 3 and 7) showed inflamed lesions devoid of scolex. CT confirmed presence of NCC in 2 cases $(25 \%)$. ELISA was done using Rida screen kit in all 8 cases and was positive in $7(87.5 \%)$ cases. Western blot was positive for one case (12.5\%) which had shown negative results with Rida screen (ELISA). Patients had a marginally elevated AEC in the range of ( 320 to 590 cells/mcL) and ESR in range of (28-40 $\mathrm{mmhg})$.

Table 12. Imaging studies used in diagnosis and confirmation of Cyst, Scolex and NCC in Intraocular Cysticercosis: (Group B) Total no. of Patients (8).

\begin{tabular}{lll}
\hline Imaging type & No. of patients & Frequency (\%) \\
\hline USG B scan confirming scolex & 6 & $(80 \%)$ \\
CT scan with contrast for Intraocular scolex detection & 2 & $(0 \%)$ \\
CT scan with contrast confirming NCC & 2 & $(20 \%)$ \\
\hline
\end{tabular}

$\mathrm{CT}$ scan= computerized axial tomography scan, NCC=Neurocysticercosis, USG B scan=Ultrasonography Brightness scan

Table 13. Serology for (Group A) and (Group B).

\begin{tabular}{lllll}
\hline & ELISA (Positive) & Western Blot (Positive) & $\begin{array}{l}\text { AEC (Normal Range: 30- } \\
\text { 350 cells/ml) }\end{array}$ & $\begin{array}{l}\text { ESR (Normal range: Men 0-22mm/ } \\
\text { hour Women 0-29mm/hour) }\end{array}$ \\
\hline Extraocular cysticercosis & 28 & 2 & $300-520$ & $20-32$ \\
Intraocular cysticercosis & 7 & 1 & $320-590$ & $18-25$ \\
\hline
\end{tabular}

$\mathrm{AEC}=$ Absolute eosinophil count, $\mathrm{ESR}=$ Erythrocyte sedimentation rate, ELISA=Enzyme linked immunosorbent assay.

\subsubsection{Management Modalities}

Two patients with confirmed NCC with features suggestive of neural irritability were started on oral phenytoin sodium and dexamethasone (Oral phenytoin 100 milligram thrice daily with dexamethasone 8 milligram thrice daily was started as initiation dose for 1 week) and adjusted thereafter as per clinical state. Among total of 8 eyes diagnosed with intraocular cysticercosis, six eyes were adviced surgery initially and two were placed under medical management with stringent observation looking for deterioration. Intraocular cysticercosis is best treated with early surgical removal. Six of these eyes which were adviced surgery consisted of cases involving TRD, intravitreal free floating cyst and subretinal cyst and were diagnosed to have lesions located posterior to equator. Hence a $23 \mathrm{G}$ PPV approach was used to access these lesions. Encirclage was done to support the posterior vitreous base in cases involving tractional retinal detachment (TRD) (case 2, 4, 6). Among the 6 eyes that underwent PPV (case 1, 2, 4, 5, 6, 8), 3 cases were of TRD with cysts which comprised of (Case 2, 4, 6), one case with intravitreal and subretinal cyst (case 2), one case with intravitreal cyst measuring nearly $6 \mathrm{DD}$ in size (case 4) (Figure 12) and one case of TRD with juxta optic nerve head subretinal cyst (case 6) (Figure 17) with presence of PVR showing good postsurgical outcome. Two cases of extra macular subretinal cyst (case 1 and case 8 ) with (case 8) presenting as active chorioretinitis (Figure 18 (preoperative image) and Figure 19 (postoperative image) and one case of submacular cyst (case 5) with thickened ERM also underwent surgery showing good (case 1, 5, 8) visual improvement. One case each of (case 3) panuveitis with chorioretinitis involving macula (Figure 20) and another of exudative RD (case 7) responded well to topical and oral steroids in early stage. Follow up of these (case 3 and case 7) showed the former having developed macula scarring with ERM (case 3) and the latter TRD (case 7) (Figure 21) both of which required PPV surgery with ERM peel. The histopathology of the paracytic cyst showed the presence of histiocytes, fibroblast, neutrophils and eosinophils along the cyst wall. Topical and oral steroid with postoperative positioning were adviced for better visual outcome. Good functional recovery was seen in $100 \%$ of cases ( 8 cases). On follow up of postoperative eyes, one patient had developed cataract and one had band infection needing surgical intervention. All 8 cases remained stable at final follow up of 6 months from date of $1^{\text {st }}$ surgery.

Mean visual acuity (1.50) at presentation improved to mean visual acuity $(0.89)$ at 6 months last follow up (P-value $<0.001)$ in Intraocular group (Group-B). Mean difference was (0.61) (Table 15).

Mean visual acuity (0.28) at presentation improved to mean visual acuity $(0.05)$ at last follow up of 12 weeks (Pvalue $<0.001$ ) in Extraocular group (Group-A). Mean difference was (0.23) (Table 16).

Spearmans rank correlation coefficient or Spearmans $\mathrm{p}$ is a nonparametric measure of rank correlation (statistical dependence between the rankings of two variables). It assesses how well the relationship between two variables can be described using a monotonic function (placed along $x-y$ axis). Values range -1 (strong negative relationship) and +1 (strong positive relationship). Values at or close to zero imply a weak or no linear relationship. Correlation coefficient values $<$ than +0.8 or $>-0.8$ are considered as borderline change.

In our study correlation coefficient related to post treatment vision in Extraocular group (Group-A) was (0.541) and $p$ value was (0.002) (Table 18) (Figure 16).

In the Intraocular group (Group-B) correlation coefficient value related to post treatment vision was (.900) and a $p$ value was (0.002) (Table-17) (Figure 15).

Data analysis to assess pretreatment and posttreatment change in visual acuity in Intraocular cysticercosis (Group-B) and Extraocular cysticercosis (Group-A): Depicted below 
Table 14. Intraocular Cysticercosis (Group-B): Management plan and Clinical outcome data.

\begin{tabular}{|c|c|c|c|c|c|c|}
\hline $\begin{array}{l}\text { Sr. No. Total } \\
\text { no. of Eyes: } 8\end{array}$ & Diagnosis & Medical treatment & Surgery & Outcome & Re-Surgery & $\begin{array}{l}\text { Six months } \\
\text { outcome from } \\
\text { Primary Surgery }\end{array}$ \\
\hline 1 & Panuveitis + SRC & Nil & $\mathrm{PPV}+\mathrm{Fax}+\mathrm{EL}+\mathrm{SOI}$ & $\begin{array}{l}\text { Anatomical } \\
\text { attached retina }\end{array}$ & Cataract & Good \\
\hline 2 & TRD+IVC+SRC & Nil & $\mathrm{BB}+\mathrm{PPV}+\mathrm{Fax}+\mathrm{EL}+\mathrm{SOI}$ & Attached retina & $\begin{array}{l}\text { Band Infection } \\
\text { (Removal) }\end{array}$ & stable \\
\hline 3 & $\begin{array}{l}\text { Panuveitis }+ \\
\text { Chorioretinitis }\end{array}$ & Topical + Oral steroids & PPV+ERM peel & Awaiting surgery & Nil & stable \\
\hline 4 & Panuveitis +TRD+IVC & Nil & $\mathrm{BB}+\mathrm{PPV}+\mathrm{Fax}+\mathrm{EL}+\mathrm{SOI}$ & Attached retina & Nil & stable \\
\hline 5 & Panuveitis+ SMC & Nil & $\begin{array}{l}\mathrm{PPV}+\mathrm{ERM} \\
\text { peel+Fax+EL+SOI }\end{array}$ & Attached retina & Nil & stable \\
\hline 6 & $\begin{array}{l}\text { Panuveitis + } \\
\text { JPPC+TRD }\end{array}$ & Nil & $\mathrm{BB}+\mathrm{PPV}+\mathrm{Fax}+\mathrm{EL}+\mathrm{SOI}$ & Attached retina & Nil & stable \\
\hline 7 & $\begin{array}{l}\text { Panuveitis +Ex RD } \\
\text { (developed TRD) }\end{array}$ & Topical + Oral steroids & $\mathrm{BB}+\mathrm{PPV}+\mathrm{Fax}+\mathrm{EL}+\mathrm{SOI}$ & Attached retina & Nil & Stable \\
\hline 9. & $\begin{array}{l}\text { NCC } \\
(2 \text { cases })\end{array}$ & $\begin{array}{l}\text { Cap. Phenytoin sodium as } \\
\text { thrice daily dosing } \\
\text { Tb. Dexamethasone } 8 \text { mgm as } \\
\text { thrice daily dosing } \\
\text { Both medications for } 1 \text { week } \\
\text { Dosage to be adjusted on basis } \\
\text { of clinical state }\end{array}$ & NIL & Stable & Nil & stable \\
\hline
\end{tabular}

* $\mathrm{CR}=$ Chorioretinitis, $\mathrm{BB}=$ Band buckle, $\mathrm{EL}=$ Endolaser ExRD= Exudative retinal detachment, ERM=Epiretinal membrane, IVC $=$ intravitreal cyst, $\mathrm{JPPC}=$ Juxta peipappilary cyst, $\mathrm{PPV}=$ Pars Plana Vitrectomy, $\mathrm{PS}=$ phenytoin sodium, $\mathrm{RD}=$ Retinal detachment, $\mathrm{SRC}=\mathrm{Subretinalcysticercosis,} \mathrm{SRM}=\mathrm{Superior}$ rectus muscles, $\mathrm{SMC}=$ Submacula cyst, $\mathrm{SOI}=$ Silicone oil injection $\mathrm{TRD}=$ Tractional retinal detachment, $+=$ plus.

Table 15. Calculation of Mean standard deviation and p value to assess pre and post treatment visual change in Intraocular group (Group-B).

\begin{tabular}{llll}
\hline & N & \multicolumn{3}{l}{ Group $=$ Intraocular } & \\
\cline { 3 - 4 } & & Mean \pm SD & Mean Difference \pm SD \\
\hline Pre treatment vision & 8 & $1.50 \pm 0.38$ & $0.61 \pm 0.24$ \\
Post treatment vision & 8 & $0.89 \pm 0.18$ & $<0.001$ \\
\hline
\end{tabular}

Table 16. Calculation of Mean standard deviation and p value to assess pre and post treatment visual change in Extraocular cysticercosis (Group-A).

\begin{tabular}{llll}
\hline & N & Group $=$ Extraocular & \\
\cline { 3 - 4 } & & Mean \pm SD & Mean Difference \pm SD \\
\hline Pre treatment vision & 30 & $0.28 \pm 0.13$ & $0.23 \pm 0.11$ \\
Post treatment vision & 30 & $0.05 \pm 0.08$ & $<0.001$ \\
\hline
\end{tabular}

Table 17. Correlations (Spearmans rho): Pre and post treatment visual acuity and p value change in intraocular cysticercosis (Group-B).

\begin{tabular}{|c|c|c|c|}
\hline \multicolumn{4}{|l|}{ Correlations } \\
\hline & & & Post treatment vision \\
\hline \multirow{3}{*}{ Spearman's rho } & \multirow{3}{*}{ Pre treatment vision } & Correlation Coefficient & $.900^{* *}$ \\
\hline & & $\mathrm{p}$ value & 0.002 \\
\hline & & $\mathrm{N}$ & 8 \\
\hline
\end{tabular}

Table 18. Correlations (Spearmans rho): Pre and post treatment visual acuity and p value change in Extraocular group (Group-A).

\begin{tabular}{|c|c|c|c|}
\hline \multicolumn{4}{|l|}{ Correlations } \\
\hline & & & Post treatment vision \\
\hline \multirow{3}{*}{ Spearman's rho } & \multirow{3}{*}{ Pre treatment vision } & Correlation Coefficient & 0.541 \\
\hline & & $\mathrm{p}$ value & 0.002 \\
\hline & & $\mathrm{N}$ & 30 \\
\hline
\end{tabular}




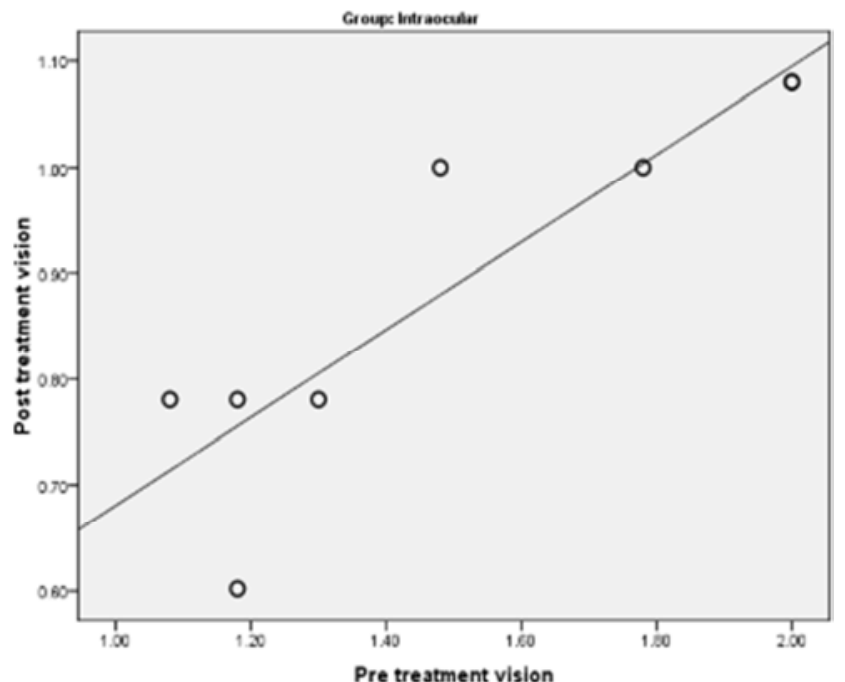

Figure 15. Graph depicting before and after treatment change in visual acuity in Intraocular cysticercosis (Group-B).

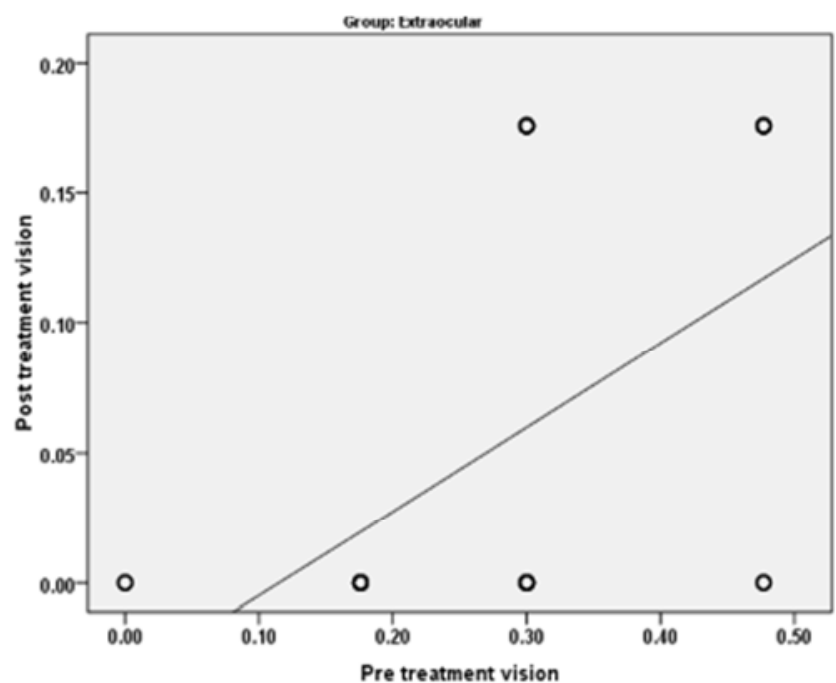

Figure 16. Graph depicting change in visual acuity before and after treatment change in Extraocular cysticercosis (Group-A).

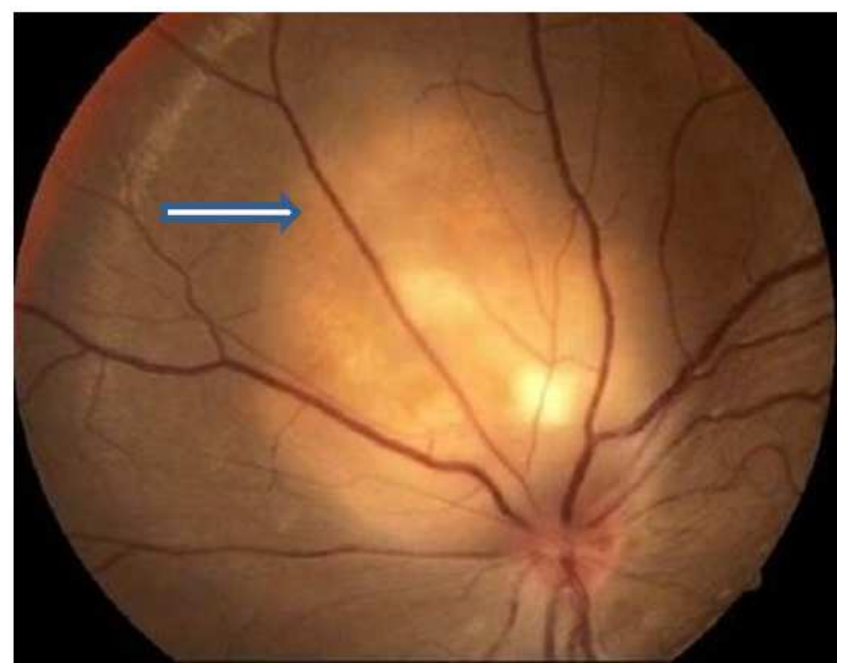

Figure 17. Clinical photograph: showing subretinal granuloma in superonasal quadrant also involving optic disc (approximate size 9 disc diopter) (white arrow).

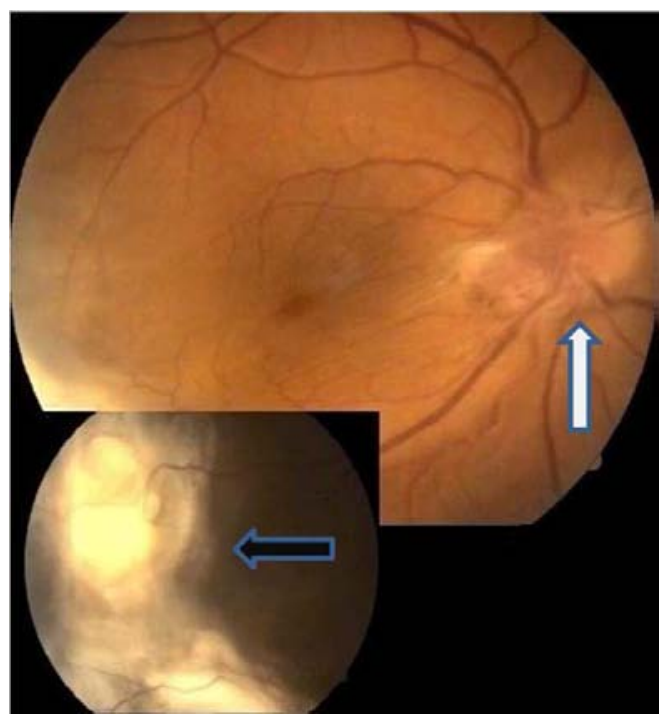

Figure 18. Clinical photograph: showing hyperemic disc with tractional retinal detachment (TRD) involving disc and macula (white arrow) along with presence of active chorioretinitis (black arrow) in inferotemporal quadrant.

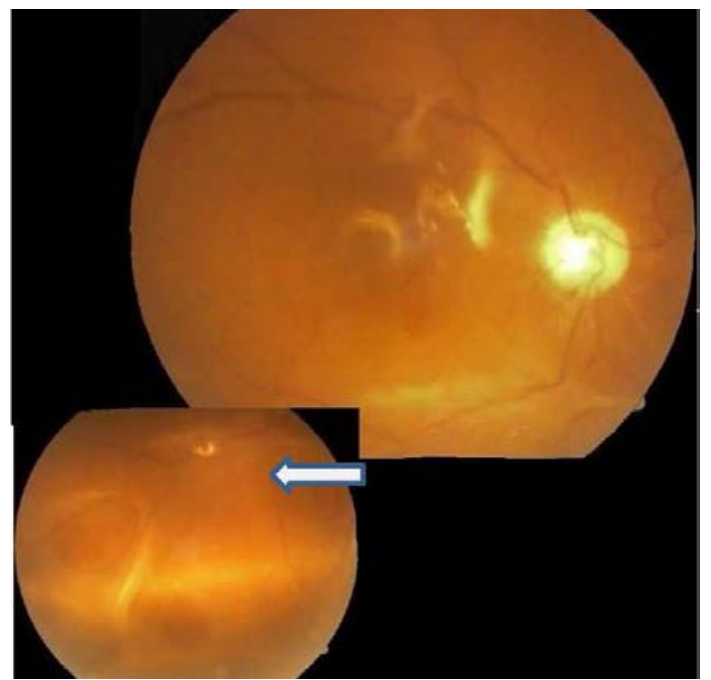

Figure 19. Clinical photograph: Showing postoperative silicone oil filled eye with disc palour and persistent inferior retinal traction (white arrow).

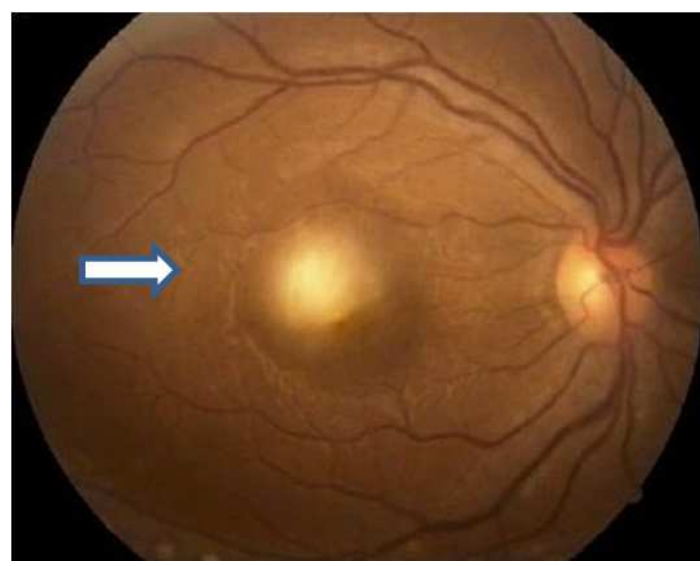

Figure 20. Clinical photograph: showing active chorioretinitis involving macula (white arrow]. 


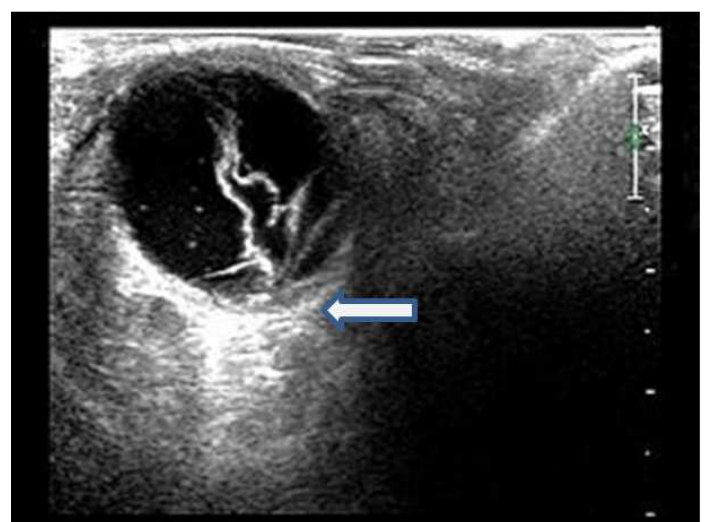

Figure 21. USG B scan: showing tractional retinal detachment (TRD) with an underlying cyst (white arrow) and a central echogenic shadow (suggestive of scolex).

\section{Discussion}

Cysticercosis may affect any portion of the visual pathway from the orbit to the visual cortex [11-13]. The most common site of involvement as per the western studies for the lesion is posterior segment [14-16]. In a study by "Kruger-Leite-et al" the distribution of cysts were $(35 \%)$ in the sub-retinal space, $(22 \%)$ in the vitreous, $(22 \%)$ in subconjuctival space, $(5 \%)$ in the anterior segment and (1\%) in the orbit [12]. In a study by "Rath et al" from Indian subcontinent, documented the presence of cyst being most prevalent in orbit showing a shift in its location in comparison to western studies. Their study documented distribution of cyst on basis of location in the decreasing order of frequency, were maximally seen in anterior orbit $(69 \%)$, subconjunctival space $(24.6 \%)$, posterior orbit $(5.8 \%)$, and least in the eyelid $(0.6 \%)$. In all $(80.7 \%)$ of patients had cysts in relation to an extraocular muscle. The superior rectus $(33.3 \%)$ was the most commonly involved extraocular muscle as per there citing [10]. In our study involving 38 cases of ocular cysticercosis, 30 cases (78.94\%) were of extraocular cysticercosis, western studies, have detected $68-74 \%$ lesions in the vitreous and subretinal locations $[1,14]$. The lesions were more prevalent in males in their second and third decade of life, gender predilection may be variable as reported by "Wender et al". Ocular cysticercosis is primarily a disease with unilateral presentation, bilateral occurance may rarely be seen [11]. Nearly $(71.05 \%)$ of our patients belonged to low socioeconomic strata and two third of patients $(65.78 \%)$ with ocular cysticercosis came from slum areas where poor hygiene and sanitation facilities may have been a contributing factor with dietary habits of poor or unhyigenicaly cooked meals with presence of nonvegetarian diet. Among our patients nonvegetarian diet was prevalent in (84.21\%) of population. Autoinfection due to the presence of tapeworm carrier in the household plays a very important role in causing cysticercosis as has been reported in a study by "Mahajan et al" [17]. Frequent detection of cysticercus lesions in young may be because of the ease to identify the parasites by simple ocular examination as compared to NCC which requires $\mathrm{CT}$ or MRI for detection and confirmation.
Fifteen $(39.47 \%)$ of our patients were less than 25 years of age, ocular cysticercosis can affect any age range from 266years [11].

Cysticercus is commonly found in skeletal muscle, subcutaneous tissue, eye and brain [11]. In our study extraocular cysticercosis (78.94\%) was more prevalent than $(21.05 \%)$ intraocular cysticercosis and (98\%) cases in extraocular cysticercosis group depicted presence of cyst, confirming findings with other studies [10]. Variable ocular presentation as periocular swelling, restricted ocular motility, proptosis and recurrent inflammation were seen in cases of orbital and adenexal cysticercosis $[18,19]$. The most common form of orbital and adenexal cysteicercosis involve the extraocular muscle with the cyst being lodged in other sites as conjunctiva, eyelid, optic nerve, retro-orbital space and rarely lacrimal sac [20]. In our study the most frequently involved muscle was superior rectus $(54.08 \%)$ as has been documented in other studies [10]. It has also been reported that subconjunctival involvement could be secondary to cyst extrusion from primary extraocular muscle site [21]. Cases involving multiple sites as NCC, levator palpebrae superioris (LPS) and superior rectus have also been reported [22]. In our case series of 30 cases of orbital cysticercosis, 26 cases (75\%) were of extraocular muscle involvement, the most common muscle being superior rectus (75\%) with three other cases of superior conjunctival cyst and one case of inferior subconjuctival cyst. Restricted ocular motility either in same or opposite direction (53.33\%) was a frequent mode of presentation seen in these case, could have been secondary to the muscle cyst or as outcome of inflammation arising due to liberation of toxins with larval death [23]. Diagnosis in orbital and adenexal cysticercosis is based on clinical, serological and radiological findings. Clinical and serological findings may not yield confirmatory diagnosis. The crucial dependence on radiological studies is thus confirmed.

In Ocular cysticercosis a typical lesion described by "Gulani et al" on USG B scan appears cystic with relatively clear contents and presence of hyperechoic area corresponding to cyst wall with attachment of scolex to inner wall, pathognomonically called as "hanging drop sign", is seen intravitreally and within the muscle [23, 24]. USG Bscan is an excellent device for monitoring the particulars of the cyst and its response to treatment. CT scans reveal a hypodense lesion with central hyperdensity which is suggestive of scolex. Seen at times is peripheral rim enhancement with presence of adjacent soft tissue inflammation. The scolex may not always be visible, following the death of the larva or rupture of the cyst after trauma or treatment [25]. The result of CT and USG B scan are comparable. USG B scan may have upper edge capturing finer details as in the ability to detect scolex within a cyst [26]. MRI has advantage over CT scan in providing better soft tissue resolution thereby detecting scolex. In other noncalcified lesions and those located at the orbital apex its imaging is invaluable $[18,26]$. MRI is extremely useful in case of myocysticercosis for detection of infection and its staging along with locating the site of cyst lodgement. 
Appearance on MRI depends on the growth stage of the parasite with host's immune response, we can typically see a round or oval lesion of fluid intensity with a distinct wall within the muscle with either presence or absence of scolex. The cyst fluid is hypointense on T1-weighted sequences and hyperintense on T2-weighted sequences due to increased protein content. Peripheral rim enhancement is seen in some cases with surrounding tissues showing presence of inflammatory odema [26, 27]. MRI contrast studies document the presence of ring enhancing lesion [18, 19, 20] which may further aide in confirming the diagnosis of deeply seated lesions [26, 28, 29]. It is important to rule out NCC with either CT or MR Imaging. NCC is of two types, parenchymal and subarachnoid. The parenchymal type responds well to medical therapy. "Escobar et al" classified parenchymal lesions into 5 types, non-cystic, vesicular, colloidal vesicular, granular nodular and calcified nodular [30]. On CT scan the cyst tends to become more hyperattenuating than cerebrospinal fluid (CSF) with perilesional hypodensity due to odema. The cyst wall becomes thick and irregular in later stages showing enhancement on post contrast sequences with or without the presence of scolex. The calcified nodular lesions are easily and best seen on CT imaging. MRI too show similar findings as $\mathrm{CT}$ on postcontrast enhancement and at this stage the lesion comes under category of single small enhancing lesion (SSEL) [31]. Without the presence of scolex it may be difficult to diagnose NCC and a presumptive diagnosis may have to be made on clinical examination. USG B scan is easy to perform, highly effective and can be repeated with ease giving adequate and desired clinical information regarding the presence of scolex. It helps in keeping a watch on the lesion and its response to medical therapy. All 38 of our patients underwent a USG B-scan with 34 eyes confirming presence of scolex $(89.47 \%)$. Imaging with MRI was adviced for 4 cases of extraocular cysticercosis (Group-A), 2 (5.26\%) for deep seated intraorbital lesions and $2(5.26 \%)$ for NCC undetectable by $\mathrm{CT}$. Neural imaging is considered mandatory prior to starting antiheminthic therapy.

In our case series immune electrophoresis test of ELISA confirmed positivity in 35 cases $(92.10 \%)$. "Garcia et al" have stated that NCC accounts for $30 \%$ of all epilepsy cases in most developing countries. The immunodiagnosis of cysticercosis is complex and strongly influenced by the course of infection, the disease burden, the cyst location, and the immune response of the host. The right way to immunodiagnosis would be to evaluate whether the serological results are consistent with clinical diagnosis and imaging results [32]. The ELISA test may not be confirmtory in all cases and Western blot is considered more specific and sensitive, should be used where ELISA results are borderline or negative [33]. In a large study carried by "Narvez et al" in Mexico City, comparing ELISA and Electroimmunotransfer Blot Assay (EITB), they studied $100 \mathrm{NCC}$ patients and 70 neurological noncysticercosis controls, searching for specific antibodies in paired samples of serum and cerebrospinal fluid using both techniques. The results showed that the EITB assay was more sensitive than the ELISA, especially when serum is being tested. Both techniques are more sensitive in cases with multiple living cysts than in cases with single cysts or calcified lesions and in patients with cysts within the parenchyma, the sensitivity of the EITB assay was higher with serum than with cerebrospinal fluid, hence the results may be variable depending on the course of infection, disease burden and immune response of host [34]. "Biswas et al" from JIPMER hospital, Pondicherry, carried out a study to standardize and evaluate dot-Enzyme linked immunosorbent assay (Dot-ELISA), a simple and rapid test for the detection of cysticercus antibodies in the serum for the diagnosis of NCC. They detected antibodies in 14 of $25(56 \%)$ clinically suspected cases of NCC, 13 of $23(56.5 \%) \mathrm{CT} / \mathrm{MRI}$ proven cases of NCC and 2 of $25(8 \%)$ each in non-cysticercal CNS infection controls and healthy controls. The test showed a sensitivity of (56.25\%), specificity of (92\%) [35]. Simple and economical test may yield much needed confirmation for diagnosis and therapeutic purpose. Though the test for ELISA-IgG / IgM for cysticercosis were positive in nearly $(92.10 \%)$ of our cases, we correlated clinical findings with imaging before confirming diagnosis.

Extraocular muscle cysticercosis has been treated successfully with oral albendazole [36-38]. As the lesions were deep seated, patients were best treated with oral albendazole and corticosteroids for duration of 4-6 weeks. The greater bioavailability of the drug due to its plasma halflife of 8-12 hours [39] with better vascularity of extraocular muscle may have been responsible for the effective clinical outcome in these patients. Corticosteroids tend to increase plasma levels of albendazole [40] and thereby control the severe inflammatory reaction to toxins, particularly when the larva dies, reducing inflammation and preventing permanent muscle fibrosis $[36,37,40]$. In those with confirmed NCC and at risk or with history of seizure disorder, a neurologist opinion was sought prior to starting antihelminthic therapy. These patients were then adviced to start antiseizure medication with oral dexamethasone. Number of visits were kept at (week 2, 4, 8, 12) making the follow up systematic and in fixed time frame. We noticed clinical improvement with resolution of lesion on clinical grounds or by USG B-scan in nearly $(65 \%)$ at 2 weeks, $(87.2 \%)$ of subjects at 4 weeks, in $(96 \%)$ at 8 weeks and nearly $(100 \%)$ at 12 weeks the results comparable with other studies $[10,21]$. As inflammatory signs resolved, residual restriction of ocular motility and diplopia in extreme position of gaze were noticed attributable to the possibility of structural damage having already occurred before inflammation was controlled with steroids. Surgery was recommended for 2 cases of conjuntival cyst which responded poorly to medical therapy $[36,41]$. These cystic lesion may be surgically challenging due to their attachment to surrounding tissue and propensity to rupture intraoperatively leading to spillover of contents and initiation of inflammatory reaction. Steroids tend to effectively control fibrotic response post-surgery, necrosis of the overlying conjunctiva has been reported [36, 42]. Post-surgery tissue 
scarring was not visible in our patient when last followed up at 6 months. The mean change in visual acuity in this group at final follow up of 12 weeks when we compared pretreatment $(0.28)$ to post treatment vision $(0.05)$ showed a difference of (0.23) which was statistically significant. Despite resolution of cysticercosis with adequate medical therapy, patients continue to have residual functional deficit as reported by "Rath et al" in their study [10].

The prevalent presentation in 8 patients with intraocular cysticercosis was blurring of vision [4]. The cyst in intraocular cysticercosis (Group-B) in our study were more frequently located in subretinal space seen in 4 eyes $(50 \%)$, intravitreal (12.5\%) space in 1 eye and lastly 1 eye harbouring single cyst each in intravitreal and subretinal space $(12.5 \%)$, in comparison to western authors which cite vitreous cavity as most frequent site $(60 \%)$ [4, 6, 12, 43]. All cases were unilateral $(100 \%)$, panuveitis was detected in $(75 \%)$ of them and posterior uveitis in $(25 \%)$. The presence of chorioretinal scar in 7 cases $(90 \%)$ indicates the entry of cysticercus to the subretinal space via choroidal circulation through short ciliary arteries gaining access to vitreous cavity via retinal break leading to formation of macula hole, retinal detachment and inciting an inflammatory reaction. It could have been responsible for the exudative retinal detachment or a picture of focal chorioretinitis found in patients of this group. Majority of our cases in (Group-B) presented with panuveitis $(75 \%)$ and posterior uveitis $(25 \%)$, a feature of inflammation arising due to release of toxins from micro perforation present in cyst wall at the time of death of parasite, live cyst could also present similarly [44, 45]. Cyst may lodge in the optic nerve near entrance to the optic canal, presenting as papillitis, undergoing removal to attain remarkable visual recovery [46].

From total of 8 cases, surgery was advised for 6 eyes initially (case 1, 2, 4, 5, 6, 8) and later for 2 eyes (case 3 and case 7) having developed complications of TRD and ERM. Since all subretinal and intravitreal lesions were located posterior to equator we used a 23 gauge PPV approach. Intraocular cysticercosis must be managed early and surgically. The cysts must be removed in totality to minimize intraoperative and postoperative reaction. Among our 8 cases, three cases (case 2, 4, 6) of TRD with PVR and intravitreal, subretinal or both type of cyst, who underwent encirclage and PPV could possibily have developed TRD as a sequelae of inflammatory process arising due to liberation of toxin from larval death [43]. Two cases of extramacular subretinal cyst (case 1 and case 8) and one case of submacular cyst (case 5) which developed thickened ERM and underwent surgery showed good functional visual improvement. We believe early removal of cyst, younger age of patient along with preoperative optical coherance tomography (OCT) assessment of retinal architecture revealing absence of scar formation could possibly have contributed towards better surgical and visual outcome [47]. One case of (case 3) panuveitis with chorioretinitis and another of exudative RD (case 7) responded initially well to topical and oral steroids needed surgical intervention for
ERM and TRD. The former developed macula scarring with ERM (case 3) requiring PPV with ERM peel [47] and the latter developed (case 7) TRD needing encirclage with PPV surgery. The role of topical and oral steroids $(1 \mathrm{mgm} / \mathrm{kg}$ body weight) is of immense importance both pre and postoperatively (2-4weeks) to control inflammation, however we should be aware of its limitation in controlling inflammation and disease progression.

Early surgical removal is the treatment of choice in intraocular cysticercosis. Site for surgery is chosen depending on location of lesion. "Sharma et al" proposed a transceleral approach for subretinal cyst located anterior to equator and transvitreal approach for intravitreal and subretinal cysts located posterior to equator. They proposed that it is crucial to precisely localize the larva when using transcelral approach more so when faced with a live organism as chances of their movement are higher when exposed to illumination [48]. We used a transvitreal micro incision vitrectomy surgery (MIVS) approach as the intravitreal and subretinal cysts were located posterior to equator [49]. A transcleral approach works best for anterior located lesions and may be more difficult [8, 50]. The availability of high speed cutters with maximum suction has greatly reduced the contact time of cyst contents and intraocular structures minimizing reaction. Successful and intact cyst removal requires separation of vitreous attachments before aspirating it [51-53]. Complete removal of posterior hyaloid is essential to prevent postoperative vitreous contraction which could induce TRD. "Topillow et al" noted that the body of cyst is usually soft compared to head or scolex which was hard and this required more than once application to engage it or aspirate it from vitreous cavity [13]. The cysticercus should be removed unharmed, avoiding its rupture and release of intracystic material in the vitreous cavity. Spillage of toxic contents following cyst rupture in situ may cause postoperative inflammation which can be dealt with adequate vitrectomy assisted with infusion of balanced salt solution to wash these products [48] followed by administration of intravitreous and systemic corticosteroids with minimal postoperative inflammation [54]. We used 360 degree encirclage (band 240; Labtician) to support posterior vitreous base in our cases.

Anatomical and functional success was achieved in 8 $(100 \%)$ cases. We assessed improvement $>4 / 200$ visual acuity as having achieved functional success. Visual acuity improved and remained stable in all 8 eyes $(100 \%)$ at final follow up of 6 months. Sharma et al reported functional improvement in $67.5 \%$ cases [48], where they defined functional success as visual acuity greater than $5 / 200$. On follow up of our cases, one patient developed cataract and another had band infection. Both cases needed surgical intervention and improved clinically in the postoperative period. Since initial visual acuity was low it is possible that the postoperative visual change may need inclusion of other parameters to be best judged (mean change in visual acuity in this group at final follow up of 6 months was, preoperative (1.50) and postoperative (0.89) with a difference of (0.61) 
was statistically significant). We assess after reviewing the data that younger age of patients, better preoperative visual acuity with lesser anterior segment inflammation, absence of preoperative retinal detachment or a localized RD, multiplicity of cysts are factors which are important in deciding the eventual outcome of surgery and the final visual recovery.

\section{Conclusion}

Extraocular cysticercosis was more prevalent than intraocular cysticercosis. Difference in their outcome and clinical results was possibly early detection and treatment. Imaging studies with immune serological test of ELISA and Western blot for anticysticercus antibodies helped in confirming the diagnosis. Western blot has an edge where ELISA results are negative. Extraocular cysticercosis can be managed well medically with good clinical outcome with oral albandazole and corticosteroids. Drug resistance responds well to praziquantal. Intraocular cysticercosisis is best treated surgically by trasscleral or transvitreal route depending on the location of cyst.

Early surgery gives best results in intraocular cysticercosis. Safer vitreoretinal surgical techniques are available promising better chances of visual recovery. Timely operative and frequent postoperative follow up help in dealing with complications safequarding the attained vision. The drawback of the study was its short duration and lesser number of patients in intraocular cysticercosis group. A larger study and longer follow up period would allow for a better assessment of various demographic features and their role in co-relation to visual outcome and recovery.

\section{Abbreviations Used}

CNS, central nervous system; CR, chorioretinitis; CT, computerized axial tomography; ELISA, enzyme linked immunosorbent assay; FFA, fundus fluorescein angiography; LRM, lateral rectus muscle; MRI, magnetic resonance imaging; NCC, neurocysticercosis; JONH, juxta optic nerve head; PPV, pars plana vitrectomy; PVR, proliferative vitreoretinopathy, SRC, subretinal cysticercosis; SRM, superior rectus muscle; TRD, tractional retinal detachment; USG B scan, ultrasonogram b-scan.

\section{Conflict of Interest}

All the authors do not have any possible conflicts of interest.

\section{Acknowledgements}

Wish to extend thanks to Akshay Nawani, Navbharat Opticals and Ms. Joyce, St. Georges School, for helping with arrangement of the manuscript. The authors have no financial or proprietary interest in any products or techniques described in this paper.

\section{References}

[1] Duke-Elder S, Perkins ES. Diseases of the uveal tract. In: Duke-Elder S [Ed]. System of Ophthalmology, Vol. 9. St. Louis: CV Mosby; 1966. p. 478.

[2] Santos R, Dalma A, Ortiz E, et al. Management of subretinal and vitreous cysticercosis: role of photocoagulation and surgery. Ophthalmology. 1979; 86: 1501-7.

[3] Franken S. Intraocular cysticercus. Ophthalmologica. 1975; 171: 7-10.

[4] King CH. Cestodes [Tapeworms]. In: Mandell G, Bennett JE, Dolin R [Eds]. Principles and Practice of Infectious Diseases, Vol. 2. New York: Churchill-Livingstone; 1995. p. 2544.

[5] Sorvillo F, Wilkins P, Shafir S, Eberhard M. Public health implications of cysticercosis acquired in the United States. Emerg Infect Dis. 2011 Jan; 17 (1): 1-6.

[6] Rajshekhar V, Joshi DD, Doanh NQ, van De N, Xiaonong Z. Taenia solium taeniosis/cysticercosis in Asia: epidemiology, impact and issues. Acta Trop. 2003 Jun; 87 (1): 53-60.

[7] Malik SR, Gupta AK, Choudhry S. Ocular cysticercosis. Am J Ophthalmol. 1968 Dec; 66 (6): 1168-71.

[8] Bartholomew RS. Subretinal cysticercosis. Am J Ophthalmol 1975; 79: 670-3.

[9] Madigubba S, Vishwanath K, Reddy GBKJ, et al. Changing trends in ocular cysticercosis over two decades: an analysis of 118 surgically excised cysts. Indian J Med Microbiol. 2007; 25 (3): 214-219.

[10] Rath S, Honavar SG, Naik M, et al. Orbital cysticercosis: clinical manifestations, diagnosis, management and outcome. Ophthalmology. 2010; 117 (3): 600-605.

[11] Wender JD, Rathinam SR, Shaw RE, Cunningham ET Jr. Intraocular cysticercosis: case series and comprehensive review of the literature. Ocul Immunol Inflamm. 2011 Aug; 19 (4): $240-5$.

[12] Kruger-Leite E, Jalkh AE, Quiroz $\mathrm{H}$, et al. Intraocular cysticercosis. Am J Ophthalmol. 1985; 99: 252-7.

[13] Topilow HW, Yimoyines DJ, Freeman HM, et al. Bilateral multifocal intraocular cysticercosis. Ophthalmology. 1981; 88: 1166.

[14] Wittig EO. Ocular cysticercosis: an epidemiological study. Arq Neuropsiquiatr. 2001; 59: 696-701.

[15] David S, Mathai E. Ocular cysticercosis-a review of 25 cases. J Assoc Physicians India. 2000; 48: 704-7.

[16] Chowdhary A, Bansal R, Singh K, et al. Ocular cysticercosis-a profile. Trop Doct. 2003; 33: 185-8.

[17] Mahajan R C 1982 Geographical distribution human cyticercosis; in Cysticercosis present state of knowledge and perspectives [eds]. A Flisser, $\mathrm{K}$ Willms, C Laclette, C Larrolde, C Ridaura and F Beltran [New York: Academic Press] pp 39-46.

[18] Sekhar GC, Honavar SG. Myocysticercosis: experience with imaging and therapy. Ophthalmology. 1999; 106: 2336-40. 
[19] Puri P, Grover AK. Medical management of orbital myocysticercosis: a pilot study. Eye [Lond]. 1998; 12: 795-9.

[20] Raoot A. Lacrimal sac cysticercosis: a rare site for manifestation. Case Rep Ophthalmol Med. 2014: 961815.

[21] Sundaram PM, Jayakumar N, Noronha V. Extraocular muscle cysticercosis-a clinical challenge to the ophthalmologists. Orbit. 2004; 23 (4): 255-262.

[22] Verma R, Jaiswal A. Multiple brain parenchymal neurocysticercosis with extraocular muscle cysticercosis affecting levator palpebral superioris and superior rectus complex: an unusual association. BMJ Case Rep. 2013; 2013.

[23] Murthy H, Kumar A, Verma L. Orbital cysticercosis - an ultrasonic diagnosis. Acta Ophthalmologica 1990; 68: 612-4.

[24] Gulani AC. Sonographic diagnosis of orbital cysticercus cyst: 'hanging drop sign'. J Diagn Med Sonogr. 1998; 14: 122-4.

[25] Nijjar IBS, Singh JP, Arora V, et al. MRI in intraocular cysticercosis - a case report. Ind J Radiol Imaging. 2005; 15 (3): 309-10.

[26] Rahalkar MD, Shetty DD, Kelkar AB, et al. The many faces of cysticercosis. Clin Radiol. 2000; 55: 668-74.

[27] Rangdal SS, Prabakar S, Dhatt SS, et al. Isolated muscular cysticercosis: a rare pseudotumor and diagnostic challenge, can it be treated nonoperatively? A report of two cases and review of literature. J Postgrad Med Educ Res. 2012; 46: 438. 60 .

[28] Topilow HW. Cysticercosis. In: Fraunfelder FT, Roy FH [Eds]. Current Ocular Therapy, 4th edition. Philadelphia: WB Saunders; 1995. p. 121.

[29] Ursekar MA, Dastur DK, Manghani DK, et al. Isolated cysticercal. infestation of extraocular muscles: CT and MR findings. AJNR Am J Neuroradiol. 1998; 19: 109-13.

[30] Escobar A, Aruffo C, Cruz-Sánchez F, Cervos-Navarro J. Neuropathologic findings in neurocysticercosis. Arch Neurobiol (Madr). 1985; 48 (3): 151-6.

[31] Nash TE, Garcia HH. Diagnosis and treatment of neurocysticercosis. Nat Rev Neurol. 2011; 7: 584-94.

[32] Garcia HH, O'Neal SE, Noh J, Handali S; Cysticercosis Working Group in Peru. Laboratory Diagnosis of Neurocysticercosis (Taenia solium). J Clin Microbiol. 2018 Aug 27; 56 (9): e00424-18.

[33] Rodriguez S, Wilkins P, Dorny P. Immunological and molecular diagnosis of cysticercosis. Pathog Glob Health. 2012 Sep; 106 (5): 286-298.

[34] Proaño-Narvaez JV, Meza-Lucas A, Mata-Ruiz O, GarcíaJerónimo RC, Correa D. Laboratory diagnosis of human neurocysticercosis: double-blind comparison of enzymelinked immunosorbent assay and electroimmunotransfer blot assay. J Clin Microbiol. 2002 Jun; 40 (6): 2115-8.

[35] Biswas R, Parija SC, Narayan SK. Dot-ELISA for the diagnosis of neurocysticercosis. Rev Inst Med Trop Sao Paulo. 2004 Sep-Oct; 46 (5): 249-52.

[36] Sekhar GC, Lemke BN. Orbital cysticercosis. Ophthalmology 1997; 104: 1599-1604.

[37] Menon V, Kumar G, Prakash P. Cysticercosis of extraocular muscle. J Pediatr Ophthalmol Strabismus 1994; 31: 126-129.

[38] Sihota R, Honavar SG. Oral albendazole in the management of extraocular muscle cysticercosis. Br J Ophthalmol 1994; 78: 621-623.

[39] Rosenthal PJ. Clinical Pharmacology of the Antihelminthic Drugs. Katzung. Basic and clinical pharmacology, Edition-12. McGraw Hill Lange; 2012. p-937-47.

[40] Jung H, Hurtado M, Medina MT, Sanchez M, Sotelo J. Dexamethasone increases plasma levels of albendazole. J Neurol 1990; 237: 279-280.

[41] Takayanagui OM, Jardim E. Therapy for neurocysticercoosis. Camparison between albendazole and praziquantel. Arch Neurol. 1992: 49: 290-4.

[42] Raina UK, Taneja S, Lamba PA, Bansal RL. Spontaneous extrusion of extraocular cysticercus cysts. Am J Ophthalmol 1996; 121: 438-441.

[43] Cardenas F, Quiroz H, Plancarte A, et al. Taenia solium ocular cysticercosis: findings in 30 cases. Ann Ophthalmol 1992; 24: $25-8$.

[44] Madan VS, Dhamija RM, Gill HS, Boparai MS, Souza PD, Sanchete PC, Bhardwaj JR. Optic nerve cysticercosis: a case report. J Neurol Neurosurg Psychiatry. 1991 May; 54 (5): 4701.

[45] Lombardo J. Subretinal cysticercosis. Optom Vis Sci. 2001 Apr; 78 (4): 188-94.

[46] Gurha N, Sood A, Dhar J, Gupta S. Optic nerve cysticercosis in the optic canal. Acta Ophthalmol Scand. 1999 Feb; 77 (1): 107-9.

[47] Kumar V, Surve A, Kumar P, Sharma A, Azad S. Submacular cysticercosis. Eur J Ophthalmol. 2020 Sep; 30 (5): NP58NP61.

[48] Sharma T, Sinha S, Shah N, et al. Intraocular Cysticercosis: Clinical Characteristics and Visual Outcome after Vitreoretinal Surgery. Ophthalmology 2003; 110 (5): 9961004.

[49] Hutton WL, Vaiser A, Snyder WB. Pars plana vitrectomy for removal of intravitreous cysticercus. Am J Ophthalmol 1976; 81: 571-3.

[50] Segal P, Mrzyglod S, Smolarz-Dudarewicz J. Subretinal cysticercosis in the macular region. Am J Ophthalmol 1964; 57: 655-64.

[51] Zinn KM, Guillory SL, Friedman AH. Removal of intravitreous cysticerci from the surface of the optic nervehead. A pars plana approach. Arch Ophthalmol 1980; 98: 714-6.

[52] Natarajan S, Malpani A, Kumar Nirmalan P, Dutta B. Management of intraocular cysticercosis. Graefes Arch Clin Exp Ophthalmol 1999; 237: 812-4.

[53] Luger MH, Stilma JS, Ringens PJ, van Baarlen J. In-toto removal of subretinal Cysticercus cellulosae by pars plana vitrectomy. Br J Ophthalmol 1991; 75: 561-3.

[54] Pantaleão GR, Borges de Souza AD, Rodrigues EB, Coelho AI. The use of systemic and intravitreous steroid in inflammation secondary to intraocular cysticercosis: case report. Arq Bras Oftalmol. 2007 Nov-Dec; 70 (6): 1006-9. 